\title{
Nickel Isotope Variations in Terrestrial Silicate Rocks and Geological Reference Materials Measured by MC-ICP-MS
}

\author{
Bleuenn Gueguen ${ }^{1,2, *}$, Olivier Rouxel ${ }^{1,2}$, Emmanuel Ponzevera $^{2}$, Andrey Bekker $^{3}$, Yves Fouquet $^{2}$
}

\author{
${ }^{1}$ Institut Universitaire Européen de la Mer, UMR 6538, Université de Bretagne Occidentale, Plouzané, France \\ 2 IFREMER, Centre de Brest, Unité Géosciences Marines, Plouzané, France \\ ${ }^{3}$ Department of Geological Sciences, University of Manitoba, Winnipeg, Canada \\ *: Corresponding author : Bleuenn Gueguen, bleuenn.gueguen@gmail.com
}

\begin{abstract}
:
Although initial studies have demonstrated the applicability of Ni isotopes for cosmochemistry and as a potential biosignature, the $\mathrm{Ni}$ isotope composition of terrestrial igneous and sedimentary rocks, and ore deposits remains poorly known. Our contribution is fourfold: (a) to detail an analytical procedure for $\mathrm{Ni}$ isotope determination, (b) to determine the $\mathrm{Ni}$ isotope composition of various geological reference materials, (c) to assess the isotope composition of the Bulk Silicate Earth relative to the $\mathrm{Ni}$ isotope reference material NIST SRM 986 and (d) to report the range of mass-dependent Ni isotope fractionations in magmatic rocks and ore deposits. After purification through a two-stage chromatography procedure, $\mathrm{Ni}$ isotope ratios were measured by MC-ICP-MS and were corrected for instrumental mass bias using a double-spike correction method. Measurement precision (two standard error of the mean) was between 0.02 and $0.04 \%$, and intermediate measurement precision for NIST SRM 986 was $0.05 \%$ (2s). Igneous- and mantle-derived rocks displayed a restricted range of $\delta^{60 / 58} \mathrm{Ni}$ values between -0.13 and $+0.16 \%$, suggesting an average BSE composition of $+0.05 \%$. Manganese nodules (Nod A1; P1), shale (SDO-1), coal (CLB-1) and a metal-contaminated soil (NIST SRM 2711) showed positive values ranging between +0.14 and $+1.06 \%$, whereas komatiite-hosted Ni-rich sulfides varied from -0.10 to $-1.03 \%$.
\end{abstract}

Keywords : nickel ; stable isotopes ; MC-ICP-MS ; geological reference materials ; Bulk Silicate Earth; abiotic fractionation

\section{Résumé :}

Bien que les premières études démontrent la pertinence des isotopes du nickel en cosmochimie et en tant que signature biologique, la composition isotopique du nickel des roches ignées et sédimentaires terrestres ainsi que celle des dépôts de minerais est encore très peu connue. Notre contribution s'organise en quatre axes, (a) détailler la procédure analytique pour la détermination des compositions isotopiques en nickel, (b) déterminer la composition isotopique de matériaux géologiques de référence variés, (c) estimer la composition isotopique de la Terre Silicatée Globale (BSE) par rapport au standard isotopique de référence de nickel NIST SRM 986, et (d) reporter la gamme des 
fractionnements isotopiques du nickel dépendants de la masse dans les roches magmatiques et les dépôts de minerais. Après purification suivant une procédure de chromatographie en deux étapes, les rapports isotopiques du nickel ont été mesurés par MC-ICP-MS puis corrigés du biais de masse instrumental par la méthode du double-spike. La fidélité de nos mesures (erreur standard de la moyenne) est comprise entre 0.02 et $0.04 \%$, et la précision de mesure intermédiaire pour le NIST SRM 986 est de $0.05 \%$ (2s). Les roches ignées et mantelliques montrent une gamme restreinte de valeurs isotopiques $\delta^{60 / 58} \mathrm{Ni}$ entre -0.13 et $+0.16 \%$, ce qui suggère une composition moyenne de la BSE à $+0.05 \%$. Les nodules de manganèse (Nod A1; P1), le shale (SDO-1), le charbon (CLB-1) et le sol contaminé en métaux (NIST SRM 271) donnent des valeurs $\delta^{60 / 58} \mathrm{Ni}$ positives comprises entre +0.14 et $+1.06 \%$, tandis que les sulfures riches en nickel présents dans les komatiites ont des valeurs négatives allant de -0.10 à $-1.03 \%$.

Mots-clés : nickel ; isotopes stables ; MC-ICP-MS ; matériaux géologiques de référence ; Terre Silicatée Globale ; fractionnement abiotique

Nickel has five naturally occurring isotopes, that is, ${ }^{58} \mathrm{Ni},{ }^{60} \mathrm{Ni},{ }^{61} \mathrm{Ni},{ }^{62} \mathrm{Ni}$ and ${ }^{64} \mathrm{Ni}$, with abundances of $68 \%, 26 \%, 1.1 \%, 3.6 \%$ and $0.9 \%$, respectively. To date, $\mathrm{Ni}$ isotope studies have been applied mainly to cosmochemical processes (e.g., Morand and Allegre 1983, Shimamura and Lugmair 1983, Tanimizu and Hirata 2006, Moynier et al. 2007, Cook et al. 2008), specifically to detect any ${ }^{60} \mathrm{Ni}$ anomaly in iron meteorites resulting from the rapid decay of ${ }^{60} \mathrm{Fe}$, which has a half-life of $2.62 \mathrm{Myr}$ (Rugel et al. 2009). As Ni occurs solely in one natural valence state $\left(\mathrm{Ni}^{2+}\right)$ in the Earth's crust, redoxcontrolled processes will not induce mass-dependent isotopic fractionations as is the case for other transition metals such as Fe, Mo, Cr and Cu (e.g., Albarede and Beard 2004, Anbar and Rouxel 2007). It implies that any observed fractionation in natural environments should be the result of either biotic processes, such as assimilation of $\mathrm{Ni}$ by micro-organisms, or abiotic processes such as chemical precipitation or adsorption in aqueous systems, or during mineral crystallisation. However, despite its potential, the understanding of $\mathrm{Ni}$ isotope systematics of terrestrial reservoirs lags behind other non-traditional isotope systems. An initial study by Tanimizu and Hirata (2006) demonstrates significant $\mathrm{Ni}$ isotope fractionation in magmatic sulfides, and only two studies subsequently report $\mathrm{Ni}$ isotope composition of crustal 
rocks (Cameron et al. 2009, Gall et al. 2012). Interestingly, a recent study demonstrated that methanogens - micro-organisms producing methane in anaerobic environments - fractionate ${ }^{60} \mathrm{Ni} /{ }^{58} \mathrm{Ni}$ ratios by up to $1.5 \%$ o by preferential incorporation of the light isotope (Cameron et al. 2009). Identification of such biosignatures in complex natural systems, however, remains uncertain. More recently, Fujii et al. (2011) report theoretical and experimental constraints on abiotic $\mathrm{Ni}$ isotope fractionations among aqueous species (i.e., chlorides, sulfides, sulfates, carbonates and hydroxides). The experimental results indicate that fractionation among $\mathrm{Ni}$ ligands, such as $\mathrm{Ni}^{2+}, \mathrm{NiSO}_{4}, \mathrm{NiCO}_{3}, \mathrm{NiHCO}_{3}{ }^{+}, \mathrm{NiCl}^{+}$and $\mathrm{NiOH}^{+}$is up to $2.5 \%$ in $\delta^{60 / 58} \mathrm{Ni}$ values, and encompasses the magnitude of fractionation during biological processes associated with methanogens (Cameron et al. 2009).

Since a growing number of studies apply Ni isotope systematics to natural samples, we aimed this study at (1) developing an experimental and analytical protocol to perform high-precision $\mathrm{Ni}$ isotopic determination in geological samples, including igneous rocks and sediments by multicollector-inductively coupled plasma-mass spectrometry (MC-ICP-MS) and using a double-spike method to correct for instrumental mass bias, (2) providing a substantial and relevant dataset of $\mathrm{Ni}$ isotope composition for RMs to allow a comparison of $\mathrm{Ni}$ isotope data among different laboratories and with the purpose of demonstrating that significant $\mathrm{Ni}$ isotope variations are detectable in a large range of rock types occurring on Earth, and (3) assessing $\mathrm{Ni}$ isotopic composition of the Bulk Silicate Earth necessary for interpreting Ni isotope fractionation in terrestrial rocks, based on analyses of mantle-derived rocks and komatiites.

\section{Materials and methods}

\section{Sample description}

Geological reference materials: Samples analysed in this study include several USGS geological reference materials, namely BHVO-2, a basalt from Hawaii (USA); BIR-1, a basalt from Iceland; DNC-1, a dolerite sampled in North Carolina (USA); DTS-1, a dunite sample from (C) 2013 The Authors. Geostandards and Geoanalytical Research (C) 2013 International Association of Geoanalysts 
the Twin Sisters area in the Washington state (USA); PCC-1, a peridotite sample from the Twin Sisters area in the Washington State (USA); Nod-A-1 and Nod-P-1 representing composites of manganese nodules from the Atlantic (Blake Plateau at $788 \mathrm{~m}$ depth) and Pacific (at $4300 \mathrm{~m}$ depth) oceans, respectively; CLB-1, a coal from the Lower Bakerstown coal bed (Bettinger Mine in the Castleman Coalfield, Maryland, USA); SDO-1, a Devonian shale from Morehead, Kentucky (USA); and the granite G-2 collected in the Sullivan quarry (Rhode Island, USA). We also analysed NIST SRM 2711, a modern soil RM affected by metal contamination (Montana, USA). Further description of these RMs and their chemical composition can be found in Govindaraju (1994). For Mn-nodule RMs, Axelsson et al. (2002) provide an intercomparison study of trace and major element concentrations. In addition, the ca. 3.8 Ga IF-G Banded Iron Formation geological reference material provided by the CRPG (Nancy, France) was also analysed.

\section{Selected samples of basalts, mantle-derived rocks and marine sediments: Fresh} volcanic glass and olivine from seafloor basalts from recent olivine-phyric pillow lava flows were selected from the site FeMO Deep at the base of Loihi Seamount (Edwards et al. 2011). These samples were recovered during the FeMO cruise by the R/V Thompson (University of Washington). Samples of serpentinised ultramafic rocks that were recovered from the Logatchev hydrothermal field (Rouxel et al. 2004, Fouquet et al. 2010) during the MICROSMOKE cruise by the R/V Atalante (Ifremer-Genavir) were also analysed. Olivine and fresh glass of the FeMO Deep basalts were separated by hand-picking to evaluate potential Ni isotope fractionation between olivine and glass, whilst serpentinite powders were prepared from bulk rocks. In addition, samples of altered and fresh basalts, and deep-sea clays (from the top of the stratigraphic sequence, in the first few metres below the seafloor) recovered at IODP site 1149 (hole C, Pacific Ocean, Eastern Japan) during cruise 185 by the R/V Joides Resolution (Plank et al. 2000, Rouxel et al. 2003) were also studied. Together with volcanic rocks available as RMs, this selected set of igneous and mantle-derived rocks allowed the estimation of the Bulk Silicate Earth (BSE) Ni isotope composition and potential Ni isotope fractionation during olivine crystallisation.

(C) 2013 The Authors. Geostandards and Geoanalytical Research (C) 2013 International Association of Geoanalysts 
Komatiite-hosted Ni-rich sulfides: Bulk rock samples comprising both komatiites and associated Ni-rich sulfide ores were analysed from two areas: the Agnew-Wiluna greenstone belt in Western Australia and the Abitibi greenstone belt in Canada (Bekker et al. 2009). The ca. 2.7 Ga Agnew-Wiluna greenstone belt is composed of a deep-marine volcanic and volcaniclastic sequence with felsic and mafic to ultramafic compositions, which locally contains large lenses of volcanogenic massive sulfides, sulfidic cherts, carbonaceous shales, and laterally variable komatiites with cumulates, thin spinifex-textured units and komatiitic basalts. Mineralisation occurs as disseminated sulfides, massive sulfide ores or sulfide aggregates comprising mostly pentlandite and pyrrhotite grains. The Mount Keith and Perseverance sites of the Agnew-Wiluna greenstone belt are among the largest komatiite-hosted Ni-Cu-PGE ore deposits. Samples from the Abitibi greenstone belt in Canada are from the Alexo mine, where Fe-Ni-Cu-PGE sulfide mineralisation occurs in a komatiitic unit with olivine cumulates (Naldrett and Mason 1968, Muir and Comba 1979, Houlé et al. 2012). Nickel-rich sulfide ores selected for this study include massive and blebby sulfides; in addition, brown olivine associated with disseminated Ni-sulfides was also analysed.

Iron meteorites: Two iron meteorites, namely Gibeon and Nantan, were selected for testing the experimental and analytical procedure because of their very high $\mathrm{Ni}$ content and previously determined $\mathrm{Ni}$ isotope compositions (Moynier et al. 2007, Cook et al. 2008).

\section{Experimental procedure}

Reagents and materials: Ultra-pure $18.2 \mathrm{M} \Omega \mathrm{cm}$ water made with a Millipore system (Milli-Q grade) was used. Both concentrated nitric and hydrochloric acids used for dissolution and column work were double-distilled from reagent-grade acids using a Cleanacids $®$ distillation apparatus (Analab, France). Acids of lower molarity were prepared from these double-distilled acids. All plastic ware was cleaned with cold $1.2 \mathrm{~mol}^{-1} \mathrm{HCl}$ (reagent grade), whereas Savillex ${ }^{\circledR}$ Teflon beakers were washed with hot $8 \mathrm{~mol} \mathrm{l}^{-1} \mathrm{HNO}_{3}$ (reagent grade).

(C) 2013 The Authors. Geostandards and Geoanalytical Research () 2013 International Association of Geoanalysts 
The double-spike used was prepared with spikes ${ }^{61} \mathrm{Ni}$ (batch 127890) and ${ }^{62} \mathrm{Ni}$ (batch 233026) provided by the Oak Ridge National Laboratory. Original spikes in metal form were dissolved separately in concentrated distilled $\mathrm{HNO}_{3}$ and evaporated at $70{ }^{\circ} \mathrm{C}$. Aliquots of the spikes were mixed together in known proportion to obtain a final double-spike solution at a concentration of $500 \mu \mathrm{g} \mathrm{g}^{-1}$ and with a ${ }^{61} \mathrm{Ni} /{ }^{62} \mathrm{Ni}$ ratio of $\sim 1$. The double-spike concentration was then determined by MC-ICP-MS using the nickel NIST SRM 986 standard solution. Considering the limited amount of spike used, we did not attempt to determine the double spike isotope composition through a gravimetric approach.

Sample digestion: Depending on their Ni concentrations, between 50 and $250 \mathrm{mg}$ of sample powder was weighed in Teflon beakers. Non-siliceous materials such as Mn-nodules, sulfides and iron meteorites were digested with $5 \mathrm{ml}$ of concentrated $\mathrm{HNO}_{3}$ and $5 \mathrm{ml}$ of $6 \mathrm{~mol} \mathrm{l}^{-1}$ $\mathrm{HCl}$, while silicate rocks were digested with a mixture of $2 \mathrm{ml}$ of concentrated $\mathrm{HF}\left(28 \mathrm{~mol}^{-1}\right.$ Trace Metal Grade or Suprapure grade) and $6 \mathrm{ml}$ of concentrated $\mathrm{HNO}_{3}$. Closed beakers were put on a hot Teflon plate at $70-80^{\circ} \mathrm{C}$ overnight and then caps were removed to allow evaporation to dryness. The solid residue was then dissolved in a mixture of concentrated $\mathrm{HNO}_{3}$ and $6 \mathrm{~mol} \mathrm{l}^{-1} \mathrm{HCl}$ and further evaporated to dryness at a temperature of $70-80{ }^{\circ} \mathrm{C}$. This latter step was repeated to achieve complete digestion of non-siliceous rocks and ensure removal of potential fluorides formed in the course of the first dissolution step of siliceous materials. Final solutions were prepared by dissolving the residue in $10 \mathrm{ml}$ of $6 \mathrm{~mol} \mathrm{l}^{-1} \mathrm{HCl}$, and one drop of optima-grade $\mathrm{H}_{2} \mathrm{O}_{2}$ was added to each sample to ensure complete oxidation of Fe.

As explained below, all sample batches, generally including twenty-four samples, were processed with duplicates of BHVO-2, DTS-1, PCC-1, Nod-P-1 or Nod-A-1 reference materials, one procedural blank and one pure mono-elemental solution of Ni (Ni Plasma Cal standard solution made by SCP Science). Note that the shale SDO-1 and the coal CLB-1 were ashed prior to digestion at $600{ }^{\circ} \mathrm{C}$ to oxidise organic matter before chemical dissolution.

(C) 2013 The Authors. Geostandards and Geoanalytical Research (C) 2013 International Association of Geoanalysts 


\section{Nickel chemical purification by ion-exchange chromatography columns: The}

chemical purification protocol used was adapted from previous work by Cameron et al. (2009) and Cook et al. (2007) and followed a two-stage procedure. The first set of ion-exchange chromatography columns (i.e., disposable polypropylene columns equipped with a large-volume $(15 \mathrm{ml})$ reservoir) was filled with $3 \mathrm{ml}$ (wet volume) of anionic resin AG1-X8 in the chloride form (BioRad 100-200 mesh). The washing procedure of the columns was begun by loading 15 $\mathrm{ml}$ of ultra-pure water, then $15 \mathrm{ml}$ of $3 \mathrm{~mol} \mathrm{l}^{-1} \mathrm{HNO}_{3}, 15 \mathrm{ml}$ of ultra-pure water, and $5 \mathrm{ml}$ of 0.24 mol $\mathrm{l}^{-1} \mathrm{HCl}$. Conditioning was carried out with $5 \mathrm{ml}$ of $6 \mathrm{~mol} \mathrm{l}^{-1} \mathrm{HCl}$ followed by the loading of a fraction of the final solutions in $6 \mathrm{~mol} \mathrm{l}^{-1} \mathrm{HCl}$ on the columns. The final solutions obtained after digestion were kept as archive solutions, and only a split was taken for ion-exchange chromatography column work. Nickel elution was achieved by passing through $15 \mathrm{ml}$ of $6 \mathrm{~mol} \mathrm{l}^{-1}$ ${ }^{1} \mathrm{HCl}$ during which $\mathrm{Fe}, \mathrm{Zn}$ and most of the $\mathrm{Co}$ and $\mathrm{Cu}$ were retained on the resin. The eluted $\mathrm{Ni}$ fraction was then taken to dryness at $100-120^{\circ} \mathrm{C}$ on a hot plate and then dissolved in $1 \mathrm{ml}$ of $0.24 \mathrm{~mol}^{-1} \mathrm{HCl}$. This solution was then purified on a second series of chromatography columns filled with a specific nickel resin commercially available from Eichrom (Ni-Spec). As discussed below, the use of the Ni-spec resin was required to ensure complete removal of all matrix elements remaining after the anion-exchange purification step, including major rock-forming elements such as alkali and alkaline earth metals.

The specific Ni-resin, made of polymethacrylate, contains a dimethylglyoxime (DMG) molecule that scavenges $\mathrm{Ni}$ at $\mathrm{pH}$ 8-9 to form an insoluble Ni-DMG complex retained on the resin. To prevent the co-precipitation of metals in the form of insoluble hydroxides, which may inhibit the formation of the Ni-DMG complex on the resin, ammonium citrate was added to buffer solutions at $\mathrm{pH}$ 8-9. About $0.5 \mathrm{ml}$ (wet volume) of $\mathrm{Ni}-\mathrm{Spec}$ resin was loaded into disposable columns and initially washed with ultrapure water. Conditioning was made using a mixture of $2.1 \mathrm{ml}$ of 0.2 mol $\mathrm{l}^{-1}$ ammonium citrate and $11.7 \mathrm{~mol} \mathrm{l}^{-1}$ optima-grade ammonia adjusted to $\mathrm{pH} \mathrm{8-9}$. Before loading the sample onto the column, $1 \mathrm{ml}$ of the initial solution in $0.24 \mathrm{~mol} \mathrm{l}^{-1} \mathrm{HCl}$ was mixed with $0.3 \mathrm{ml}$ of $1 \mathrm{~mol} \mathrm{l}^{-1}$ ammonium citrate, and $0.1 \mathrm{ml}$ of $11.7 \mathrm{~mol} \mathrm{l}^{-1}$ optima-grade ammonia to maintain a $\mathrm{pH}$ of $8-9$. The matrix was then eluted with $4.2 \mathrm{ml}$ of mixed ammonium citrate and ammonia solution and $4 \mathrm{ml}$ of ultra-pure water. Nickel was quantitatively eluted from the resin

(C) 2013 The Authors. Geostandards and Geoanalytical Research (c) 2013 International Association of Geoanalysts 
with $8 \mathrm{ml}$ of $3 \mathrm{~mol} \mathrm{l}^{-1} \mathrm{HNO}_{3}$, which ensured oxidation and destruction of the Ni-DMG complex with nitric acid. This technique, therefore, prevented any regeneration and reuse of the resin. The eluted Ni solution was evaporated to dryness on a hot plate at $90{ }^{\circ} \mathrm{C}$ and the residue dissolved in $0.28 \mathrm{~mol} \mathrm{l}^{-1} \mathrm{HNO}_{3}$ when it was ready for isotope determination.

Before chemical purification through the Ni-spec column, a known amount of double-spike solution was added to each sample. As explained below, the double-spike amount was chosen to be equal to the $\mathrm{Ni}$ content in the sample. Chemistry yields were determined using the measured spike/natural ratio (i.e., ${ }^{62} \mathrm{Ni} /{ }^{58} \mathrm{Ni}$ ). Chemistry blanks were also spiked, which enabled us to determine procedural blank values. Chemistry yields through Ni-spec resin were generally better than $85 \%$, while yields through AG1-X8 resin were always quantitative. In contrast to another recently published experimental procedure for nickel purification (Gall et al. 2012), our yields were not dependent on the geological matrix and amount of nickel loaded on the column. Nickel procedural blanks were generally $c a .3-4 \mathrm{ng}$, and since between 0.5 and $>1 \mu \mathrm{g}$ of nickel was generally processed through chemistry (see footnotes in Tables 3, 4, 5, 6 and 7), this blank level was considered negligible and did not require any correction. However, when smaller sample sizes are analysed, care should be taken to reduce these blanks.

\section{Mass spectrometry procedure and data reduction scheme}

Delta notation: Nickel isotope composition is expressed following the conventional stable isotope delta notation, i.e., sample isotopic ratios are expressed relative to a standard ratio as per mil deviation (\%o) following:

$\delta^{\mathrm{x} / 58} \mathrm{Ni}=\left(\mathrm{R}_{\mathrm{spl}} / \mathrm{R}_{\mathrm{NIST}}-1\right) \times 1000$

where $\mathrm{R}_{\text {spl }}$ and $\mathrm{R}_{\mathrm{NIST}}$ are the isotopic ratios ${ }^{\mathrm{x}} \mathrm{Ni} /{ }^{58} \mathrm{Ni}$ of the unknown sample and the nickel NIST SRM 986 reference material, respectively; ${ }^{\mathrm{x}} \mathrm{Ni}$ stands for one of the following three isotopes:

(C) 2013 The Authors. Geostandards and Geoanalytical Research @ 2013 International Association of Geoanalysts 
${ }^{60} \mathrm{Ni},{ }^{61} \mathrm{Ni}$ or ${ }^{62} \mathrm{Ni}$, and the light isotope, ${ }^{58} \mathrm{Ni}$, is placed in the denominator (it is also the most abundant). However, note that following Coplen's (2011) recommendation, omission of the multiplication factor of 1000 in the delta notation could be permitted because technically it belongs to the $\%$ symbol rather than to the $\delta$ notation. The ratio that will be used to describe the data in this study is ${ }^{60} \mathrm{Ni} /{ }^{58} \mathrm{Ni}$ and it will be reported as $\delta^{60 / 58} \mathrm{Ni}$.

MC-ICP-MS settings: All samples were analysed on a Neptune (Thermo-Electron) MCICP-MS operated at the Pôle Spectrométrie Océan (PSO) located at IFREMER, Centre de Brest, France. This instrument was equipped with nine Faraday cups that allowed simultaneous measurement of ${ }^{58} \mathrm{Ni},{ }^{60} \mathrm{Ni},{ }^{61} \mathrm{Ni}$ and ${ }^{62} \mathrm{Ni},{ }^{63} \mathrm{Cu}$ and ${ }^{65} \mathrm{Cu}$ isotopes, as well as isobaricallyinterfering Fe monitored at mass ${ }^{57} \mathrm{Fe}$. The instrument was run in either a medium or high massresolution mode, but the medium-resolution mode was sufficient to resolve argide and oxide interferences on $\mathrm{Ni}$ isotopes as discussed below. Nickel ion beam intensity in a medium resolution mode with the ApexQ was typically 50-75 V/ $\mathrm{g} \mathrm{ml}^{-1}$ on ${ }^{58} \mathrm{Ni}$. Although both sample and skimmer cones ( $\mathrm{X}$ cone) were made of $\mathrm{Ni}$, their contribution to the $\mathrm{Ni}$ isotopic ratios of samples was negligible, since the measured instrumental blank signal intensity on mass ${ }^{58} \mathrm{Ni}$ did not exceed $0.5 \mathrm{mV}$ and $0.2 \mathrm{mV}$ on the spiked isotope ${ }^{62} \mathrm{Ni}$. This also indicated that the use of other cone types (e.g., Al or Pt cones) was unnecessary, as already demonstrated by Moynier et al. (2007). The inlet system was either a spray chamber (i.e., Stable Introduction System (SiS) coupled with a $50 \mu 1 \mathrm{~min}^{-1}$ PFA micro-concentric nebuliser) or an ApexQ (ESI, USA) desolvation introduction system.

Fifty measurement cycles, each having an integration time of $4 \mathrm{~s}$, were performed on samples, whereas washout consisted of ten measurement cycles, each with an integration time of $4 \mathrm{~s}$. The total time required per analysis was, therefore, approximately 4 min (analysis plus washout).

The main interferences on $\mathrm{Ni}$ isotopes included $\mathrm{Fe}\left(\right.$ e.g., ${ }^{58} \mathrm{Fe}$ on ${ }^{58} \mathrm{Ni}$ ), Ar or other element (e.g., Ca) oxides generated in the argon plasma with identical masses (e.g., ${ }^{40} \mathrm{Ar}^{18} \mathrm{O}^{+}$on ${ }^{58} \mathrm{Ni}^{+}$), and 
doubly-charged ions (e.g., ${ }^{124} \mathrm{Xe}^{2+}$ on ${ }^{62} \mathrm{Ni}$ ). The latter was negligible considering that (1) Xe has a high first-ionisation potential and (2) no ${ }^{124} \mathrm{Xe}^{2+}$ was measured on mass 62 in the blank solution; and (3) the use of ultrapure argon resulted in negligible Xe intensity, as previously reported by Fehr et al. (2004) for Te isotope measurements with potential important isobaric interferences from Xe isotopes. The other major potential spectral interference on ${ }^{64} \mathrm{Ni}$ is from ${ }^{64} \mathrm{Zn}$. Since the Faraday cup configuration of the mass spectrometer did not allow simultaneous measurement of the interference-free ${ }^{66} \mathrm{Zn}$ isotope, we did not attempt to measure the ${ }^{64} \mathrm{Ni}$ isotope in this study. Argide and oxide interferences included ${ }^{36} \mathrm{Ar}^{24} \mathrm{Mg}^{+}$and ${ }^{44} \mathrm{Ca}^{16} \mathrm{O}^{+}$on ${ }^{60} \mathrm{Ni}^{+}$; ${ }^{36} \mathrm{Ar}^{25} \mathrm{Mg}^{+}$, and ${ }^{38} \mathrm{Ar}^{23} \mathrm{Na}^{+}$on ${ }^{61} \mathrm{Ni}^{+} ;{ }^{36} \mathrm{Ar}^{26} \mathrm{Mg}^{+},{ }^{38} \mathrm{Ar}^{24} \mathrm{Mg}^{+}$, and ${ }^{46} \mathrm{Ca}^{16} \mathrm{O}^{+}$on ${ }^{62} \mathrm{Ni}^{+} ;{ }^{23} \mathrm{Na}^{35} \mathrm{Cl}^{+}$, ${ }^{40} \mathrm{Ar}^{18} \mathrm{O}^{+}$, and ${ }^{42} \mathrm{Ca}^{16} \mathrm{O}^{+}$on ${ }^{58} \mathrm{Ni}^{+}$. Medium-resolution (and also high-resolution) modes allowed us to resolve polyatomic interferences on ${ }^{58} \mathrm{Ni}^{+}$, which still remained significant even when using the ApexQ (ESI, USA) system due to the production of argon oxide.

Fe isotope interference correction: Consideration of isobaric interference from $\mathrm{Fe}$ was critical given that it affects the major isotope ${ }^{58} \mathrm{Ni}$. Therefore, even if Fe was quantitatively separated from Ni during chemical purification prior to analysis, ${ }^{57} \mathrm{Fe}$ was systematically measured and the interference of ${ }^{58} \mathrm{Fe}$ on ${ }^{58} \mathrm{Ni}$ was corrected using Equation 2:

$\left({ }^{58} \mathrm{Fe} /{ }^{57} \mathrm{Fe}\right)_{\text {measured }}=\left({ }^{58} \mathrm{Fe} /{ }^{57} \mathrm{Fe}\right)_{\text {natural }} \cdot\left(\mathrm{M}_{58} / \mathrm{M}_{57}\right){ }^{\mathrm{fFe}}$

where $\left({ }^{58} \mathrm{Fe} /{ }^{57} \mathrm{Fe}\right)_{\text {measured }}$ is the raw ratio measured by MC-ICP-MS; $\left({ }^{58} \mathrm{Fe} /{ }^{57} \mathrm{Fe}\right)_{\text {natural }}$ is the corrected natural iron ratio; $\mathrm{M}_{58}$ is the atomic weight of ${ }^{58} \mathrm{Fe} ; \mathrm{M}_{57}$ is the atomic mass of ${ }^{57} \mathrm{Fe}$; and $\mathrm{f}_{\mathrm{Fe}}$ is the mass discrimination factor considered equivalent to the mass discrimination factor of nickel $\left(\mathrm{f}_{\mathrm{Ni}}\right)$, which is generally around 1.8. The discrimination factor was estimated based on measurements of iron and nickel mixed solution at the beginning of each analytical session. It is important to note that this correction is only an approximation since the natural Fe isotope ratio may vary by as much as 3\%o per mass unit (e.g., Dauphas and Rouxel 2006). However, this correction was negligible for $\mathrm{Ni}$ isotopes $(<0.1 \%$ o) given that iron interference was very small

(C) 2013 The Authors. Geostandards and Geoanalytical Research (C) 2013 International Association of Geoanalysts 
after chemical separation, when iron was quantitatively removed from the analyte. Additionally, we estimated the effect of iron on the isotopic composition of nickel by measuring several NIST SRM 986 solutions doped with various amounts of iron. The results (see Table 1) show that minor amounts of iron (Fe/Ni ratios from 0.001 to 0.010 ) did not produce any bias in Ni isotope ratios. The Ni isotope composition of NIST SRM 986 Fe-doped solutions was corrected for instrumental mass bias using the calibrator-bracketing method (a non-doped NIST SRM 986 solution was measured before and after each Fe-doped NIST SRM 986 solution), which explains why the analytical precision was lower than for the samples corrected with the double-spike.

\section{Inter-elemental correction of $\mathrm{Ni}$ instrumental mass bias using $\mathrm{Cu}$ isotopes: This}

method is based on adding a known amount of $\mathrm{Cu}$ standard solution (i.e., NIST SRM 976), which is used to correct for instrumental mass bias. As demonstrated in previous studies (e.g., Marechal et al. 1999), instrumental mass bias on MC-ICP-MS follows an exponential massfractionation law with the fractionation factor "f" being specific for each element. The linear relationship (plot not shown) between logarithms of Ni isotope ratios of NIST SRM 986 and $\mathrm{Cu}$ isotope ratios of NIST SRM 976 confirmed that (1) $\mathrm{Cu}$ isotopes follow the same exponential mass fractionation law as $\mathrm{Ni}$ isotopes; $(2) \mathrm{f}_{\mathrm{Cu}} / \mathrm{f}_{\mathrm{Ni}}$ was constant during individual analytical sessions, which allowed us to use $\mathrm{f}_{\mathrm{Cu}}$ determined on NIST SRM 976 (Equation 3) to calculate $\mathrm{f}_{\mathrm{Ni}}$ (Equation 4).

$\left(\mathrm{R}_{\text {meas }} / \mathrm{R}_{\text {true }}\right)_{\mathrm{Cu}}=\left(\mathrm{M}^{65} \mathrm{Cu} / \mathrm{M}^{63} \mathrm{Cu}\right)^{\mathrm{fCu}}$

$\left(\mathrm{R}_{\text {meas }} / \mathrm{R}_{\text {true }}\right)_{\mathrm{Ni}}=\left(\mathrm{M}^{60} \mathrm{Ni} / \mathrm{M}^{58} \mathrm{Ni}\right)^{\mathrm{fNi}}$

Considering that nickel recovery yield on the Ni-spec resin purification step ranged from $85 \%$ to $99 \%$, it is possible that $\mathrm{Cu}$-corrected $\mathrm{Ni}$ isotope compositions of purified samples were affected by significant analytical artefacts. Hence, this correction method is only suitable for Ni-rich ores

(C) 2013 The Authors. Geostandards and Geoanalytical Research (C) 2013 International Association of Geoanalysts 
and iron meteorites purified through anion-exchange resin as used in previous studies (Quitté $e t$ al. 2006, Moynier et al. 2007, Cook et al. 2008). In addition, this approach was used to compare $\mathrm{Ni}$ isotope data obtained using $\mathrm{Cu}$-doping and double-spike methods.

Determination of the double-spike composition: In theory, double-spike composition can be determined either gravimetrically or after normalisation to a known isotopic reference material, such as NIST SRM 986 (Gramlich et al. 1989). In practice, however, the gravimetric technique does not yield a sufficiently precise composition for small quantities of spike. In addition, isotope ratios might be influenced by the type of instrument and instrumental settings, and it is therefore critical to cross-calibrate both isotope reference materials and spike on the same instrument. Indeed, as discussed previously by Siebert et al. (2001), uncertainties on the natural spike and RM isotope composition do not introduce bias providing that both double spike and $\mathrm{RM}$ are calibrated on the same instrument and that isotope data are expressed as $\delta^{60 / 58} \mathrm{Ni}$ values.

The isotopic composition of NIST SRM 986 was first determined by internal normalisation using $\mathrm{a}^{60} \mathrm{Ni} /{ }^{58} \mathrm{Ni}$ ratio of $0.385199 \pm 0.000728(2 s)$ (Gramlich et al. 1989). This ratio was then used to calculate the instrumental mass-discrimination factor $\mathrm{f}_{\mathrm{Ni}}$, which allowed the calculation of other isotopic ratios, i.e., ${ }^{62} \mathrm{Ni} /{ }^{58} \mathrm{Ni}$ and ${ }^{61} \mathrm{Ni} /{ }^{58} \mathrm{Ni}$. The isotopic composition of the nickel double spike was then determined using the $\mathrm{Cu}$-doping correction method to determine the true ${ }^{60} \mathrm{Ni} /{ }^{58} \mathrm{Ni}$, ${ }^{61} \mathrm{Ni} /{ }^{58} \mathrm{Ni}$ and ${ }^{62} \mathrm{Ni} /{ }^{58} \mathrm{Ni}$ ratios of the spike vs. NIST SRM 986. A Cu-doped pure standard solution was used to calculate the $\mathrm{f}_{\mathrm{Cu}} / \mathrm{f}_{\mathrm{Ni}}$ ratio, which was then applied to $\mathrm{Cu}$-doped pure doublespike solution. In order to avoid cross-contamination between the standard solution and the double-spike solution, an extended rinse time and "on-peak zero" method was used. Results are presented in Table 2.

Double spike correction scheme: The double-spike calculation procedure was based upon the method described by Siebert et al. (2001) for Mo isotope determination. The doublespike method can be visualised as a three-dimensional diagram where axes represent the three 
measured isotopic ratios as specified above. Line and plane intercepts, defined by isotopic compositions of the double-spike, standard solution and sample measured by MC-ICP-MS, are used to determine fractionation factors between the measured and corrected isotopic ratios (Albarede and Beard 2004). A template was established to calculate those plane intercepts by making iterative calculations to account for both natural and instrumental fractionation factors, which were applied subsequently to the measured raw isotope ratios. At least two nested iterations were run to properly obtain the fractionation factors. The template could be performed either on an Excel ${ }^{\mathrm{TM}}$ spreadsheet or using Matlab ${ }^{\mathrm{TM}}$.

In order to obtain satisfactory precision, fifty analytical cycles ( $\sim$ min of total integration time) were acquired during sample analysis. Each sample analysis was bracketed by the measurements of NIST SRM 986 nickel solutions at the same nickel concentration and spike/standard ratio as that of the samples. The double spike method offers several advantages relative to the $\mathrm{Cu}$-doping or sample-calibrator bracketing methods by allowing: (i) the correction of potential isotopic fractionation during chemical separation through $\mathrm{Ni}$-spec resin; (ii) the determination of precise and accurate nickel concentrations of samples using the isotopic dilution method; (iii) better overall analytical precision (because corrected ratios were less affected by the stability of the instrumental mass bias and the assumption that $\mathrm{f}_{\mathrm{Cu}} / \mathrm{f}_{\mathrm{Ni}}$ remained constant throughout the analytical session); and (iv) accurate measurement of very small amounts of nickel, down to 50 ng, by MC-ICP-MS.

\section{Results of analytical method development}

\section{Measurement precision and limit of detection}

For each analysis, the measurement precision is reported as a two standard error of the mean calculated on fifty cycles of measurement during MC-ICP-MS acquisition. With the doublespike correction, the precision of $\delta^{60 / 58} \mathrm{Ni}$ values was usually around $\pm 0.02-0.04 \%$ (2SE) for samples with nickel concentrations ranging from $100 \mathrm{ng} \mathrm{g}^{-1}$ to $1 \mu \mathrm{g} \mathrm{g}^{-1}$. Precision at lower (C) 2013 The Authors. Geostandards and Geoanalytical Research @ 2013 International Association of Geoanalysts 
concentrations was assessed by analysing NIST SRM 986 solution at different concentrations. In Figure 1, the two standard error of the mean calculated for each analysis is reported against the nickel concentrations, and shows that below $30 \mathrm{ng} \mathrm{g}^{-1}$ the precision slightly deteriorated to about $\pm 0.07 \%$, but became worse at $10 \mathrm{ng} \mathrm{g}^{-1}$ and lower concentrations, e.g., $2 \mathrm{SE}=0.59 \%$ at $2 \mathrm{ng} \mathrm{g}^{-1}$ of nickel.

For optimum measurement precision during isotope measurements, we usually ran samples with nickel concentrations of 100-200 $\mathrm{ng} \mathrm{g}^{-1}$, when using either the ApexQ or SiS introduction systems on the MC-ICP-MS instrument.

\section{Intermediate measurement precision of NIST SRM 986 and RMs}

A spiked NIST SRM 986 solution was measured before and after each sample in a manner similar to the calibrator-sample bracketing (CSB) analysis. We found that the Ni isotope ratios of NIST SRM 986 calculated using the double-spike method may deviate by up to $0.2 \%$ per mass unit between analytical sessions but remained constant within 0.02-0.05\%o $(2 s)$ during each analytical session. As a result, we normalised delta values of the samples relative to the average NIST SRM $986 \mathrm{Ni}$ isotope ratios determined during the same analytical session. The large data set acquired for NIST SRM 986 allowed us to evaluate the measurement precision under intermediate precision conditions of the $\mathrm{Ni}$ isotope composition determined by the double-spike method. For instance, $2 s$ determined using all NIST SRM 986 delta values calculated so far gave a value of $0.045 \%$ o for 320 measurements.

The precision under intermediate precision conditions was also estimated for certified reference materials (BHVO-2, PCC-1, DTS-1, DNC-1, BIR-1, Nod-A-1 and Nod-P-1) using duplicate analyses of these samples (see footnotes of Table 3 for details). A value of $0.041 \%$ ( $2 s$ ) calculated for BHVO-2 duplicates $(n=11)$ was similar to the precision under repeatability

(C) 2013 The Authors. Geostandards and Geoanalytical Research (C) 2013 International Association of Geoanalysts 
conditions. This suggests that the chemical purification method did not introduce additional variability in isotope measurements. One of the BHVO-2 basalt duplicates was spiked after a complete purification procedure to evaluate potential $\mathrm{Ni}$ isotope fractionation during chemical purification. Although only one sample was spiked subsequent to the purification procedure, the results gave similar values, i.e., $0.006 \pm 0.041 \%$ ( $2 s)$ and $-0.067 \pm 0.017 \%$ (2SE) for the samples spiked before and after sample purification, respectively. This indicates that the incomplete recovery of $\mathrm{Ni}$ through the $\mathrm{Ni}$-resin did not introduce Ni isotope fractionation (Table 3). Other RMs, i.e., PCC-1, Nod-A-1, Nod-P-1, BIR-1, DNC-1 and DTS-1, were also analysed in duplicate and their $\delta^{60 / 58} \mathrm{Ni}$ values generally did not deviate by more than $0.069 \%$ ( $2 s$; Tables 3 and 7), which is similar to the intermediate measurement precision of NIST SRM 986. It is also important to note that for BHVO-2 the isotopic composition and recovery remained invariant even for different amounts of sample material processed through the chemistry, i.e., between 0.2 and $5 \mu \mathrm{g}$ of nickel. In addition, the mono-elemental solution of Ni-PCal (Ni Plasmacal®, SCP science) processed through the entire chromatography procedure (Figure 2) yielded an average value of $0.020 \pm 0.065 \%$ o $(2 s, \mathrm{n}=24)$, which is similar to that for direct analysis of Ni-PCal standard solution.

Alternatively, another method for estimating the precision under intermediate precision conditions would be to pool all the data and to calculate the standard deviation using Equation (5) (Steele et al. 2011):

$s^{2}=k^{-1} \sum_{i} d_{i}^{2}$

where $s$ is the standard deviation, $k$ is the degree of freedom and $d$ is the deviation from the mean. This method is appropriate when conditions of sample processing and measurement are similar. From data in Table 3 with five samples and 21 degrees of freedom (not including the BHVO-2 spiked after the purification procedure), $2 s$ was $0.045 \%$; from data in Table 7 with six samples and 23 degrees of freedom (not including single measurements on USGS G-2, IF-G and

(C) 2013 The Authors. Geostandards and Geoanalytical Research @ 2013 International Association of Geoanalysts 
NIST SRM 2711), $2 s$ was 0.053\%o. Taking samples from both Tables 3 and 7 (i.e., eleven samples and 44 degrees of freedom), $2 s$ was $0.050 \%$. Hence, the $2 s$ value of $0.045 \%$ calculated as the measurement reproducibility of NIST SRM 986 (see above) is comparable to the standard deviation calculated following the methodology of Steele et al. (2011), indicating that in our study both methods were adequate for assessing the measurement reproducibility ('external precision').

\section{Optimum spike/sample ratio for $\mathrm{Ni}$ isotope determination}

Several tests were undertaken with different spike/sample ratios (between 0.03 and 8) to evaluate the robustness of the double-spike correction. For each sample used for the tests, the concentration of NIST SRM 986 was kept fixed and different amounts of double-spike were added to make final solutions with different spike/sample ratios, which is tantamount to ${ }^{61} \mathrm{Ni} /{ }^{58} \mathrm{Ni}$ ratios. To simply visualise the meaning of the spike/sample ratio, one should consider that nickel from the NIST SRM 986 solution is equivalent to the nickel present in a natural sample (denominator of the ratio), whereas nickel from the double-spike solution is the spike (numerator of the ratio). Instead of simply reporting a concentration ratio (concentration of spike/concentration of NIST SRM 986), the spike/sample ratio was calculated using measured intensities (corrected for instrumental mass bias), isotopic masses, and true ${ }^{61} \mathrm{Ni} /{ }^{58} \mathrm{Ni}$ ratios of NIST SRM 986 and the double-spike mixture.

As shown in Figure 3, only under-spiked samples may not be properly corrected. Indeed, spike/sample ratios lower or equal to 0.6 yielded $\delta^{60 / 58} \mathrm{Ni}$ values ranging between $-0.05 \pm 0.02 \%$ o (2SE) and $-0.24 \pm 0.06 \%$ for NIST SRM 986, whereas ratios higher than 0.6 yielded $\delta^{60 / 58} \mathrm{Ni}$ values clustering around $0.01 \pm 0.02 \%$. Even spike/sample ratios of up to 7 gave consistent $\delta^{60 / 58} \mathrm{Ni}$ values of $0.04 \pm 0.02 \%$. Although an optimum precision was obtained for spike/sample ratios between 0.7 and 8 , we used a spike/sample ratio $\sim 1$ throughout this study.

(C) 2013 The Authors. Geostandards and Geoanalytical Research @ 2013 International Association of Geoanalysts 
The Matlab® template constructed by Rudge et al. (2009) allowed us to further evaluate the optimum spike/sample ratio. Calculations indicated that the best results were obtained with spike/sample ratios between $\sim 0.6$ and $\sim 4$, which is consistent with our results.

\section{Evaluation of potential matrix effect and chemical purification efficiency}

Chemical purification efficiency was checked for a number of RMs (e.g., manganese nodules, basalts and shale) by measuring concentrations of matrix elements with an ICP-Quadrupole (ICP-Q-MS, X-series II) at PSO, Brest. Potassium, Na, Ca, Cr, Mn, Fe, Mo and Co concentrations in purified samples were all below the detection limit of the instrument. The estimated separation efficiency factor, defined as the mass ( $\mathrm{g}$ ) of an element loaded on resin divided by the mass of the element remaining after purification, was $>10^{6}$ for $\mathrm{Na}$ and $\mathrm{Mg}, \sim 10^{6}$ for $\mathrm{Cu}$ and $>10^{7}$ for $\mathrm{Mn}$. Titanium was found more difficult to separate with a separation factor as low as $10^{3}$. On the other hand, $\mathrm{Zn}$ was well separated (separation efficiency factor better than $10^{6}$ ), although care should be taken to avoid $\mathrm{Zn}$ contamination during sample preparation. Since

${ }^{64} \mathrm{Ni}$ was not considered in our double-spike calculations and final results, potential isobaric interference from ${ }^{64} \mathrm{Zn}$ was not critical for our study. Iron was not detected in all analysed solutions (separation efficiency $>>10^{6}$ ), which suggests that iron was quantitatively separated during the chemical procedure even if samples had high amounts of iron.

Potential matrix effects were further assessed using several NIST SRM 986 solutions doped separately with $\mathrm{Ca}$ and S. Since several Ni-rich sulfides were analysed without Ni-spec resin column purification, we tested the influence of sulfur on the instrumental mass bias with $\mathrm{S} / \mathrm{Ni}$ ratios between 2 and 0.5 in analysed solutions. The same was also done with $\mathrm{Ca}$, which is a good proxy for matrix-forming elements in silicate rocks. Calcium is also a source of potential isobaric interferences from calcium oxides (e.g. ${ }^{40} \mathrm{Ca}^{18} \mathrm{O}$ on ${ }^{58} \mathrm{Ni}$ ). Matrix-doped nickel solutions were analysed using a calibrator-sample bracketing method and without a nickel double-spike in order to monitor all natural $\mathrm{Ni}$ isotope ratios. As shown in Table 1, the results suggest that isobaric

(C) 2013 The Authors. Geostandards and Geoanalytical Research @ 2013 International Association of Geoanalysts 
interferences and changes in instrumental mass bias were insignificant for element/Ni ratios between 1 and 0.5 , yielding $\delta^{60 / 58} \mathrm{Ni}$ values of $-0.18 \pm 0.14 \%$ o $(2 s)$ and $0.02 \pm 0.14 \%$ (2s) for $\mathrm{Ca} / \mathrm{Ni}=1$ and $\mathrm{S} / \mathrm{Ni}=1$, respectively. These results also imply that the medium-resolution mode resolved major isobaric interferences from $\mathrm{CaO}$. Note that similar to the Fe-doping tests (see section on MC-ICP-MS settings), measured Ni isotope values for NIST SRM 986 doped with Ca and $\mathrm{S}$ were corrected for instrumental mass bias using the sample-calibrator bracketing method. The reported precision is the two standard deviation value based on replicate measurements of non-doped NIST SRM 986.

\section{Comparison between $\mathrm{Cu}$-doping and double-spike correction methods for instrumental mass bias}

Several Ni-rich sulfides as well as iron meteorites (i.e., Ni-rich meteorites) were analysed and corrected for instrumental mass bias using two different methods. One method involved sample purification through anion-exchange resin and instrumental mass bias correction based on $\mathrm{Cu}$ doping. The second method involved purification through the entire procedure and double-spike correction. As shown in Figure 4, values calculated with the two methods fall within

uncertainties for the total range of $\delta^{60 / 58} \mathrm{Ni}$ values from $-0.60 \%$ o to $0.40 \%$. These results further validate the reliability of the double-spike data reduction scheme.

\section{Sample analysis results and discussion}

\section{Assessment of the Bulk Silicate Earth (BSE) Ni isotope composition}

It is important to have an estimate of the Bulk Silicate Earth value in order to interpret and compare $\mathrm{Ni}$ isotope fractionation in natural samples. Hence, our approach was to measure Ni isotope values in various igneous rocks, including oceanic basalts and Archaean komatiites. The

(C) 2013 The Authors. Geostandards and Geoanalytical Research @ 2013 International Association of Geoanalysts 
former yield an estimate of the modern mantle isotope composition, whereas the latter may represent the early Earth's mantle isotope composition.

Igneous and ultramafic rock samples: As presented in Table 3 and Figure 5, mafic and ultramafic RMs (i.e., basalt, dunite and peridotite) closely clustered within a range of $\delta^{60 / 58} \mathrm{Ni}$ values between $-0.10 \%$ and $+0.15 \%$; BHVO-2 gave a near zero $\delta^{60 / 58} \mathrm{Ni}$ value $(0.01 \pm 0.04 \%$, $2 s, \mathrm{n}=11$ ). Table 4 and Figure 5 display isotopic and chemical composition of the basalt samples from Hawaii (Loihi Seamount) and serpentinite from the Mid-Atlantic Ridge (Logatchev field). Fresh pillow basalts from Loihi Seamount were selected since they were probably derived from the deep enriched Earth's mantle as indicated by their high ${ }^{3} \mathrm{He} /{ }^{4} \mathrm{He}$ ratios (Kurz et al. 1983). Therefore, they might represent the most primitive mantle composition, which is important for determining the BSE Ni isotope composition. Fresh glass material from Loihi yielded a value of $+0.07 \%$, while hand-picked olivine crystals displayed a slightly more positive value of $+0.10 \%$. Serpentinite from the Logatchev hydrothermal field had a $\delta^{60 / 58} \mathrm{Ni}$ value of $-0.13 \%$, whereas peridotite PCC- 1 had the value of $+0.12 \%$ and dunite DTS -1 had a composition of $-0.07 \%$. In addition, fresh and altered basalts recovered at IODP core site 1149 (Plank et al. 2000, Rouxel et al. 2003) were also analysed (Table 5 and Figure 5). They gave $\delta^{60 / 58} \mathrm{Ni}$ values between -0.03 and $+0.10 \%$, without any significant difference between fresh and altered basalts, and are in agreement with $\mathrm{Ni}$ isotope values for other mafic igneous rocks reported in this study. In summary, all mantle-derived rocks analysed in this study, i.e., RMs (BHVO-2, BIR-1, DNC-1, DTS-1 and PCC-1) and fresh and altered basalts from Loihi seamount and IODP core 1149 , displayed a small range of $\delta^{60 / 58} \mathrm{Ni}$ values, less than $0.1 \%$, which is too close to the analytical uncertainty to be considered significant.

For comparison, previously published $\delta^{60 / 58} \mathrm{Ni}$ values (figure 5 in Cameron et al. 2009) are systematically heavier with values up to $+0.34 \pm 0.08 \%$ o $(2 s)$ for PCC-1 and $+0.13 \pm 0.03 \%$ (2s) for BHVO-2. In contrast, Gall et al. (2012) obtained results similar to ours for both PCC-1 and BHVO-2 $(\sim+0.1 \% \circ)$. The small discrepancy in the data, although minor, might be related to reference material heterogeneity or to an as yet unclear difference in analytical methods.

(C) 2013 The Authors. Geostandards and Geoanalytical Research (C) 2013 International Association of Geoanalysts 
Ni isotope composition of deep-sea clays: Deep-sea clays were collected at IODP site 1149 along with altered and fresh basalts described above (Plank et al. 2000). Clay minerals are the most common component of sediments on the oceanic seafloor; hence they represent an important sedimentary reservoir on Earth. Deep-sea sediments are the repository of materials of both detrital and chemical origin derived from the continents. Therefore, their Ni isotope composition can be taken as representative of the average composition of the continental crust. As expected, $\delta^{60 / 58} \mathrm{Ni}$ values of +0.04 and $+0.02 \%$ o for deep-sea clays (Table 5, Figure 5) clearly fall in the range of values obtained for igneous and ultramafic rocks in our study.

Ni isotope composition of komatiite-hosted Ni-sulfide ores: Our komatiite samples were representative of Ni-sulfide-mineralised ultramafic magmas. While some samples were dominated by pentlandite mineralisation (AX-1, AX-2, MC-1, TD21, MKTD76), others were composed of almost pure komatiitic materials (B and A) and two samples were olivine mineral separates (BE-1 and BE-2). An unexpected large range of Ni isotope values was measured on these samples, ranging from -0.10 to $-1.03 \%$ (Table 6 , Figure 5), but the most negative $\delta^{60 / 58} \mathrm{Ni}$ values, from -0.62 to $-1.03 \%$, were determined on samples with elevated content of pentlandite, whereas olivine minerals and pure komatiite samples were close to modern basalt values, from 0.26 to $-0.10 \%$.

The choice of these samples was essentially motivated by our attempt to assess a value for the BSE composition, and we did not expect to obtain such a large range of variation in the $\mathrm{Ni}$ isotope composition of komatiites. Regardless of the, as yet unclear, mechanism of Ni isotope fractionation in komatiites, our results clearly demonstrate that significant abiotic fractionation of $\mathrm{Ni}$ isotopes took place during the magmatic processes that formed these rocks. This interpretation is further confirmed by recent $\mathrm{Ni}$ isotope data for Archaean Ni-rich magmatic sulfides from Zimbabwe that show a systematic enrichment in low atomic number isotopes to values as low as $-0.82 \pm 0.02 \%$, with most values clustering around $-0.40 \%$ o (Hofmann et al.

(C) 2013 The Authors. Geostandards and Geoanalytical Research @ 2013 International Association of Geoanalysts 
submitted). Therefore, it seems very likely that negative Ni isotope values measured for these komatiites reflect the contribution of Ni-rich sulfides.

All Archaean komatiite samples and associated Ni-sulfide mineralisation from this study previously yielded negative $\Delta^{33} \mathrm{~S}$ values (Table 6; Bekker et al. 2009). Bekker et al. (2009) suggest that these negative values reflect assimilation of sulfur processed through an oxygenpoor atmosphere, where it underwent mass-independent fractionation during photochemical reactions. Although $\mathrm{S}$ isotopes indicate crustal contribution for sulfur during komatiite emplacement, which promoted sulfide saturation to form sulfide mineralisation, $\mathrm{Ni}$ is unlikely to be sourced from a crustal reservoir and is most probably linked with partial mantle melting. Therefore, the observed Ni isotope fractionations are solely the result of magmatic processes occurring at high temperatures (i.e., abiotic fractionation). Iron isotope composition of the same samples was less variable, with a range from +0.36 to $-0.30 \%$ interpreted as being the result of either crustal contamination or high-temperature fractionation (Bekker et al. 2009). Hightemperature Fe isotope fractionation has been documented by Teng et al. (2008), who show that magmatic differentiation in the Kilauea Iki lava lake (Hawaii) produced Fe isotope fractionations of $\sim 0.2 \%$. Since the range of Ni isotope variations reported in our study was $\sim 0.90 \%$, it indicates that $\mathrm{Ni}$ isotopes are at least as sensitive as Fe isotopes to high-temperature processes and crystallisation effects in magmatic systems. Although a detailed discussion of parameters that govern $\mathrm{Ni}$ isotope fractionation at high temperature is beyond the scope of this paper, these promising results coupled to their ubiquitous occurrence in mantle rocks mean that $\mathrm{Ni}$ isotopes could be potentially used to investigate crystallisation processes at the magmatic system scale.

Ni isotope composition of the Bulk Silicate Earth: Mantle heterogeneity and hightemperature mass-dependent fractionation processes have been inferred from studies of stable isotope systems ranging from traditional low atomic number isotopes, O and S (e.g., Eiler 2001), to non-traditional isotopes, including Mg and Fe (e.g., Young and Galy 2004, Dauphas and Rouxel 2006, Teng et al. 2008). Our results for Ni isotopes are, to some extent, consistent with inferences from studies of other stable isotope systems, precluding a straightforward estimate of

(C) 2013 The Authors. Geostandards and Geoanalytical Research (C) 2013 International Association of Geoanalysts 
the Bulk Silicate Earth value. However, since we observed a narrow range in $\delta^{60 / 58} \mathrm{Ni}$ values from mantle-derived rocks, between $\sim-0.1$ and $+0.1 \%$, we feel confident to ascribe the BSE composition to the average value of common basalts and mantle-derived rocks, which is $+0.05 \pm$ $0.05 \%$ (measurement reproducibility). Our BSE estimate is slightly lower than that of $+0.179 \pm$ 0.036\%o determined by Steele et al. (2011) on Japanese basalt JP-1 and dunite DTS-2. The large range of mantle-derived rocks analysed in our study and the inclusion of common sedimentary minerals such as deep-sea clays improves our understanding of the Ni isotope composition of BSE.

\section{Ni isotopes in selected RMs}

Organic matter-rich samples: Samples containing high contents of organic matter, namely SDO-1 Devonian Ohio shale (Morehead, Kentucky, USA) and CLB-1 coal (Maryland, USA) gave $\delta^{60 / 58} \mathrm{Ni}$ values of $+0.58 \%$ and $+0.47 \%$, respectively (Table 7 and Figure 5). These positive values relative to BSE provide strong evidence for $\mathrm{Ni}$ isotope fractionation in lowtemperature environments with interesting prospects for future studies. Although shales are generally considered as a proxy for bulk crustal composition (e.g., Turekian and Wedepohl 1961), organic-rich shales are characterised by authigenic enrichments of redox-sensitive trace metals such as $\mathrm{Mo}, \mathrm{Ni}, \mathrm{U}, \mathrm{Cu}, \mathrm{V}$ and $\mathrm{Zn}$, leading to metal/Al ratios well above crustal values (e.g., Algeo and Maynard 2004, Brumsack 2006, Tribovillard et al. 2006, Scott et al. 2008, Scott et al. 2011). In marine sediments nickel has a strong affinity to organic matter, forming organometallic complexes, and with iron sulfides (e.g., pyrite), which may form either in the water column or during diagenesis in sediments. Hence, positive Ni isotope values in marine organic matter-rich sediments probably reflect the contribution of isotopically heavy nickel sources, derived either directly from seawater or in association with organic matter.

Mn-nodule RMs: Geological reference materials of manganese nodules (Nod-A-1 and

Nod-P-1) that represent composite samples from the Atlantic and Pacific oceans gave $\delta^{60 / 58} \mathrm{Ni}$ values of $+1.03 \%$ and $+0.36 \%$, respectively. Mn-nodules are typically enriched in transition metals such as $\mathrm{Ni}, \mathrm{Cu}, \mathrm{Zn}$ and $\mathrm{Co}$ and form in deep-sea sediments generally at water depths (C) 2013 The Authors. Geostandards and Geoanalytical Research (C) 2013 International Association of Geoanalysts 
between 4 and $6 \mathrm{~km}$. They consist of concentrically laminated Fe-Mn oxyhydroxides precipitated at the sediment-water interface. The two Mn-nodule RMs were prepared from a large number of individual Mn-nodules collected from the Atlantic and Pacific oceans (Table 7 and Figure 5). These nodules had been analysed previously for other isotopic systems (Table 8) such as Fe (Dideriksen et al. 2006), Zn and Cu (Bigalke et al. 2010, Chapman et al. 2006), Cd (Horner et al. 2010, Schmitt et al. 2009, Cloquet et al. 2005), Mo (Barling et al. 2001) and Tl (Nielsen et al. 2004; Rehkämper et al. 2002), highlighting differences in their isotopic composition with the exception of Mo (Anbar 2004) and Cd isotopes. The difference in Ni isotope composition between these two nodules is larger (per mass unit) than for any other studied isotope system, and indicates that $\mathrm{Ni}$ isotopes are particularly sensitive to mechanisms involved in the formation of nodules, compared with other metal isotope systems. Several processes could be inferred to explain such variations: (1) diagenetic processes through which metals contained in subsurface sediments (e.g., associated with organic matter) were released into pore waters and then scavenged onto Mn-oxides during nodule growth, (2) adsorption of metals directly from seawater onto oxyhydroxides, (3) biological productivity in surface waters, which could result in a high supply of organic matter to the sediments providing metals to pore waters during organicmatter re-mineralisation, (4) in situ biological activity, specifically that of microbial mats, which have been observed to cover entire nodule surfaces. It is clear that more detailed investigations regarding the contribution of each of these mechanisms to the composition of polymetallic nodules, as well as a larger dataset, are needed to clearly establish which of these processes are responsible for variations in the Ni isotope composition of Fe-Mn nodules.

Rehkämper et al. (2002) argue that variations in Tl isotope ratios of Mn-nodules reflect equilibrium fractionation during preferential adsorption of heavy $\mathrm{Tl}$ isotopes onto Mn-oxides in a closed system developed in pore waters, which are an important source of metals for Mn-nodule growth. Similarly, Ni isotopes might be affected by this mechanism as revealed by experimental results on nickel adsorption on Fe-Mn oxides (Gueguen et al. 2011). Alternatively, Horner et al. (2010) argue that Cd isotopes incorporated with Mn-oxides into Fe-Mn crusts were not fractionated compared with seawater Cd probably because of the high ionic strength of seawater. The same might hold true for Mn-nodule Cd isotope compositions that probably reflect biotic

(C) 2013 The Authors. Geostandards and Geoanalytical Research (C) 2013 International Association of Geoanalysts 
fractionations by micro-organisms rather than fractionation during adsorption on $\mathrm{Fe}-\mathrm{Mn}$ oxides (Schmitt et al. 2009). The chemical behaviour of nickel in seawater is akin to that of cadmium (and zinc), for example, in their depletion in surface waters upon their uptake by phytoplankton. We therefore suggest that $\mathrm{Ni}$ isotopes in precipitated marine Fe-Mn oxides might have been also affected by biological activity, although this remains to be demonstrated.

Other RMs corresponding to major terrestrial reservoirs: The metal-contaminated soil sample NIST SRM 2711 (Table 7 and Figure 5) was found to have a $\delta^{60 / 58} \mathrm{Ni}$ value of $+0.14 \%$, which is very close, within uncertainty, to lithogenic sediments such as loess and Nile river sediment with $\delta^{60 / 58} \mathrm{Ni}$ values of +0.10 and $+0.13 \%$, respectively (Cameron et al. 2009) and to Pacific deep-sea clays (see above). In contrast, granite G-2 with very low nickel content was significantly enriched in heavy $\mathrm{Ni}$ isotopes with a $+0.43 \%$ value (Table 7 and Figure 5 ), suggesting variability in $\mathrm{Ni}$ isotope ratios within common continental rocks. Finally, the Iron Formation IF-G sample displayed an enrichment in heavy Ni isotopes of $+0.45 \%$ (Table 7 ).

\section{Ni isotope composition of iron meteorites}

Our main goals in measuring iron meteorite samples were to implement our experimental and analytical procedure on Ni-rich rocks and to compare our data with results from previous studies. Since the first $\mathrm{Ni}$ isotope measurements were made on meteoritic materials to study nucleosynthetic processes (Birck and Lugmair 1988, Cook et al. 2006, 2007, Moynier et al. 2007, Regelous et al. 2008, Chen et al. 2009), the available dataset of Ni isotope determinations mainly concerns extraterrestrial reservoirs with the main focus on mass-independent Ni isotope variations.

The Gibeon and Nantan Iron meteorites both displayed fairly similar positive $\delta^{60 / 58} \mathrm{Ni}$ values (see Table 5; $2 s$ calculated on duplicate analyses) of $+0.26 \%$ and $+0.31 \%$, respectively, consistent with data in Cook et al. (2008), who obtained a $\delta^{62 / 58} \mathrm{Ni}$ value of $+0.37 \pm 0.09 \%$ on Gibeon Iron. Our values are also in full agreement with the range of $\delta^{60 / 58} \mathrm{Ni}$ values measured in iron (C) 2013 The Authors. Geostandards and Geoanalytical Research (C) 2013 International Association of Geoanalysts 
meteorites by Cameron et al. (2009) and Steele et al. (2011), i.e., 0.24 to 0.36\%o. Other meteorites analysed by Moynier et al. (2007) and Cameron et al. (2009), including chondrites, are also enriched in high atomic number isotopes and have a range of values between $+0.02 \%$ o and $+0.80 \%$ (only few meteorites in these datasets have negative $\mathrm{Ni}$ isotope values). It is however important to note that Moynier et al. (2007) report their isotopic ratios with respect to the Aesar ICP-MS Ni standard solution batch No 066110910 and expressed their results as per mass unit.

As discussed by Regelous et al. (2008), the observed isotopic variations among iron meteorites and chondrites, which are mass-independent, are likely to be the result of mixing within the protosolar nebula of mineralogical phases with different nucleosynthetic origin. Steele et al. (2011) and Regelous et al. (2008) suggest that each iron meteorite class had their protolith formed in a restricted region of the protosolar nebula as was previously demonstrated for the precursor materials to the different classes of chondrites. The overlap between massindependently fractionated $\mathrm{Ni}$ isotope values of iron meteorites and chondrites suggests that the source regions of parent bodies for the different classes of chondrites and iron meteorites might have also overlapped. In addition, the range of Ni isotope values among iron meteorites is also suggestive of lateral heterogeneity in the early Solar System. Alternatively, based on massdependent Ni isotope compositions, Moynier et al. (2007) and Cook et al. (2007) argue that all meteorites follow the same mass-dependent fractionation line as terrestrial samples and indicate fractionation from a common isotopic pool, which was homogenised in the solar nebula. In this interpretation, nickel isotope variations in meteorites reflect physicochemical reactions between distinct phases (e.g., solid-vapour, metal-silicate). Recently, Huh et al. (2009) experimentally demonstrated an isotopic fractionation of at least $-0.3 \%$ o between metallic and silicate phases at magmatic temperature $\left(800{ }^{\circ} \mathrm{C}\right)$, with the metal being enriched in low atomic number isotopes. Altogether, these results suggest that significant $\mathrm{Ni}$ isotope fractionations may have occurred during Earth's core segregation and that Ni isotope composition of the Earth after its accretion may have differed from the Bulk Silicate Earth composition developed after the early differentiation of the metallic core.

(C) 2013 The Authors. Geostandards and Geoanalytical Research (C) 2013 International Association of Geoanalysts 


\section{Conclusions}

In this paper, investigation of deep-sea clays, and mantle-derived rocks of RMs and mafic and ultramafic igneous rocks and minerals such as fresh and altered basalts, komatiites and olivine crystals allowed us to establish the isotopic composition of the Bulk Silicate Earth at $\delta^{60 / 58} \mathrm{Ni}=$ $+0.05 \pm 0.05 \%$. We report here the $\mathrm{Ni}$ isotope composition of selected geological reference materials, which show a range of $\delta^{60 / 58} \mathrm{Ni}$ values more than $1 \%$ o. Interestingly, both Fe-Mn nodules and organic matter-rich shales have positive $\delta^{60 / 58} \mathrm{Ni}$ values, suggesting either biotic or inorganic $\mathrm{Ni}$ isotope fractionations in aqueous environments. We also found that bulk rock samples of komatiites and associated $\mathrm{Ni}$-sulfide mineralisation display a range of $\delta^{60 / 58} \mathrm{Ni}$ values from -0.10 to $-1.03 \%$, indicating that fractionation in high-temperature magmatic systems can explain some variations in the Ni isotope composition of natural samples. We infer that Ni-rich sulfides with negative $\delta^{60 / 58} \mathrm{Ni}$ values affected the $\mathrm{Ni}$ isotope composition of komatiites, which otherwise, as shown by the least mineralised komatiite samples, have Ni isotope compositions close to that of BSE with a near zero value. This is an important finding since it emphasises that $\mathrm{Ni}$ isotope fractionations are not an unique biosignature, as was recently inferred (Cameron et al. 2009), but they can be also produced by abiotic processes such as high-temperature magmatic processes and, potentially, by low-temperature processes during co-precipitation of $\mathrm{Ni}$ with $\mathrm{Fe}$ Mn oxides (Gueguen et al. 2011). Therefore, the Ni isotope composition of specific terrestrial reservoirs (e.g., magmatic and sedimentary rocks) relevant to the biogeochemical Ni cycle might significantly deviate from the BSE value, and, more importantly, our results demonstrate that Ni isotope fractionations are systematic, i.e., positive fractionations characterise low-temperature processes, while negative fractionations mark high-temperature processes. Finally, we have demonstrated that for $\mathrm{Ni}$ isotopes the double-spike correction method is appropriate for measuring a broad range of sample matrices from silicate rocks to metalliferous deposits, including sulfides, and a large range of Ni concentrations. The method allowed us to measure small but meaningful fractionations of more than ten times the analytical precision even when small amounts of Ni were processed through chemistry and determined by MC-ICP-MS. The new results for RMs and analytical methods presented here should help to make Ni isotope

(C) 2013 The Authors. Geostandards and Geoanalytical Research (C) 2013 International Association of Geoanalysts 
measurements more straightforward, and more frequently utilised in future studies of terrestrial and planetary materials.

\section{Acknowledgements}

We thank Céline Liorzou and Yoan German for laboratory assistance, Jean-Alix Barrat for iron meteorite samples, and Marco Fiorentini for samples of komatiites and associated Ni-sulfide mineralisation from Canada and Western Australia. We thank Harry Elderfield and Jeffrey Sorensen for their thoughtful comments on the first draft of this manuscript. Two anonymous reviewers and the editor Thomas Meisel are gratefully thanked for their constructive comments and corrections to this manuscript. The study was supported by funding from Ifremer, the European Marie-Curie ISOMAR project (European Reintegration grant \#FP7 \#247837), and Europôle Mer. Participation by AB was supported by NSERC Discovery Grant and IFREMER visiting scientist grant.

\section{References}

\section{Albarede F. and Beard B. (2004)}

Analytical methods for non-traditional isotopes. Reviews in Mineralogy and Geochemistry, 55, 113-152.

\section{Algeo T.J. and Maynard J.B. (2004)}

Trace-element behavior and redox facies in core shales of Upper Pennsylvanian Kansas-type cyclothems. Chemical Geology, 206, 289-318.

\section{Anbar A.D. (2004)}

Molybdenum stable isotopes: Observations, interpretations and directions. Reviews in Mineralogy and Geochemistry, 55, 429-454.

(C) 2013 The Authors. Geostandards and Geoanalytical Research @ 2013 International Association of Geoanalysts 
Anbar A.D. and Rouxel O. (2007)

Metal stable isotopes in paleoceanography. Annual Review of Earth and Planetary Sciences, 35, 717-746.

Axelsson M.D., Rodushkin I., Ingri J. and Ohlander B. (2002)

Multielemental analysis of Mn-Fe nodules by ICP-MS: Optimisation of analytical method. Analyst, 127, 76-82.

Barling J., Arnold G.L. and Anbar A.D. (2001)

Natural mass-dependent variations in the isotopic composition of molybdenum. Earth and Planetary Science Letters, 193, 447-457.

Bekker A., Barley M.E., Fiorentini M.L., Rouxel O.J., Rumble D. and Beresford S.W. (2009)

Atmospheric sulfur in Archaean komatiite-hosted nickel deposits. Science, 326, 1086-1089.

Bigalke M., Weyer S., Kobza J. and Wilcke W. (2010)

Stable $\mathrm{Cu}$ and $\mathrm{Zn}$ isotope ratios as tracers of sources and transport of $\mathrm{Cu}$ and $\mathrm{Zn}$ in contaminated soil. Geochimica et Cosmochimica Acta, 74, 6801-6813.

Birck J.L. and Lugmair G.W. (1988)

Nickel and chromium isotopes in Allende inclusions. Earth and Planetary Science Letters, 90, 131-143.

Boyle E.A., John S. Abouchami W., Adkins J.F., Echegoyen-Sanz Y., Ellwood M., Flegal A.R., Fornace K., Gallon C., Galer S., Gault-Ringold M., Lacan F., Radic A., Rehkämper M., Rouxel O., Sohrin Y., Stirling C., Thompson C., Vance D., Xue Z.C. and Zhao Y. (2012)

GEOTRACES IC1 (BATS) contamination-prone trace element isotopes $\mathrm{Cd}, \mathrm{Fe}, \mathrm{Pb}, \mathrm{Zn}, \mathrm{Cu}$ and Mo intercalibration. Limnology and Oceanography: Methods, 10, 653-665.

(C) 2013 The Authors. Geostandards and Geoanalytical Research @ 2013 International Association of Geoanalysts 
Brumsack H.J. (2006)

The trace metal content of recent organic carbon-rich sediments: Implications for Cretaceous black shale formation. Palaeogeography, Palaeoclimatology, Palaeoecology, 232, 344-361.

Cameron V., Vance D., Archer C. and House C.H. (2009)

A biomarker based on the stable isotopes of nickel. Proceedings of the National Academy of Sciences of the United States of America, 106, 10944-10948.

Chapman J.B., Mason T.F.D., Weiss D.J., Coles B.J. and Wilkinson J.J. (2006)

Chemical separation and isotopic variations of $\mathrm{Cu}$ and $\mathrm{Zn}$ from five geological reference materials. Geostandards and Geoanalytical Research, 30, 5-16.

Chen J.H., Papanastassiou D.A. and Wasserburg G.J. (2009)

A search for nickel isotopic anomalies in iron meteorites and chondrites. Geochimica et Cosmochimica Acta, 73, 1461-1471.

Cloquet C., Rouxel O., Carignan J. and Libourel G. (2005)

Natural cadmium isotopic variations in eight geological reference materials (NIST SRM 2711, BCR 176, GSS-1, GXR-1, GXR-2, GSD-12, Nod-P-1, Nod-A-1) and anthropogenic samples, measured by MC-ICP-MS. Geostandards and Geoanalytical Research, 29, 95-106.

Cook D.L., Clayton R.N., Wadhwa M., Janney P.E. and Davis A.M. (2008)

Nickel isotopic anomalies in troilite from iron meteorites. Geophysical Research Letters, 35, doi: 10.1029/2007GL032431.

Cook D.L., Wadhwa M., Clayton R.N., Dauphas N., Janney P.E. and Davis A.M. (2007)

Mass-dependent fractionation of nickel isotopes in meteoritic metal. Meteoritics and Planetary Science, 42, 2067-2077.

Cook D.L., Wadhwa M., Janney P.E., Dauphas N., Clayton R.N. and Davis A.M. (2006)

(C) 2013 The Authors. Geostandards and Geoanalytical Research @ 2013 International Association of Geoanalysts 
High precision measurements of non-mass-dependent effects in nickel isotopes in meteoritic metal via multicollector ICP-MS. Analytical Chemistry, 78, 8477-8484.

Coplen T.B. (2011)

Guidelines and recommended terms for expression of stable-isotope-ratio and gas-ratio measurement results. Rapid Communications in Mass Spectrometry, 25, 2538-2560.

Dauphas N. and Rouxel O. (2006)

Mass spectrometry and natural variations of iron isotopes. Mass Spectrometry Reviews, 25, 831-832.

Dideriksen K., Baker J.A. and Stipp S.L.S. (2006)

Iron isotopes in natural carbonate minerals determined by MC-ICP-MS with a Fe-58-Fe-54 double spike. Geochimica et Cosmochimica Acta, 70, 118-132.

Edwards K.J., Glazer B.T., Rouxel O.J., Bach W., Emerson D., Davis R.E., Toner B.M., Chan C. S., Tebo B.M., Staudigel H. and Moyer C.L. (2011)

Ultra-diffuse hydrothermal venting supports Fe-oxidizing bacteria and massive umber deposition at $5000 \mathrm{~m}$ off Hawaii. The ISME Journal, 1-11.

Eiler J.M. (2001)

Oxygen isotope variations of basaltic lavas and upper mantle rocks. Reviews in Mineralogy and Geochemistry, 43, 319-364.

Fouquet Y., Cambon P., Etoubleau J., Charlou J.L., Ondréas H., Barriga F.J.A.S., Cherkashov G., Semkova T., Poroshina I., Bohn M., Donval J.P., Henry K., Murphy P. and Rouxel O. (2010)

Geodiversity of hydrothermal processes along the mid-atlantic ridge and ultramafic-hosted mineralization: A new type of oceanic $\mathrm{Cu}-\mathrm{Zn}-\mathrm{Co}-\mathrm{Au}$ volcanogenic massive sulfide deposit. Geophysical Monograph Series, 188, 444pp.

(C) 2013 The Authors. Geostandards and Geoanalytical Research @ 2013 International Association of Geoanalysts 
Fujii T., Moynier F., Dauphas N. and Abe M. (2011)

Theoretical and experimental investigation of nickel isotopic fractionation in species relevant to modern and ancient oceans. Geochimica et Cosmochimica Acta, 75, 469-482.

Gall L., Williams H., Siebert C. and Halliday A. (2012)

Determination of mass-dependent variations in nickel isotope compositions using double spiking and MC-ICP-MS. Journal of Analytical Atomic Spectrometry, 27, 137-145.

Fehr M.A., Rehkämper M. and Halliday A.N. (2004)

Application of MC-ICP-MS to the precise determination of tellurium isotope compositions in chondrites, iron meteorites and sulfides. International Journal of Mass Spectrometry, 232, 83-94.

Fiorentini M., Rosengren N., Beresford S., Grguric B. and Barley M. (2007)

Controls on the emplacement and genesis of the MKD5 and Sarah's Find Ni-Cu-PGE deposits, Mount Keith, Agnew-Wiluna Greenstone Belt, Western Australia. Mineralium Deposita, 42, 847-877.

\section{Govindaraju K. (1994)}

1994 compilation of working values and sample description for 383 geostandards.

Geostandards Newsletter, 18 (Special Issue), 158pp.

Gramlich J.W., Machlan L.A., Barnes I.L. and Paulsen P.J. (1989)

Absolute isotopic abundance ratios and atomic weight of a reference sample of nickel. Journal of Research of the National Institute of Standards and Technology, 94, 347-356.

Gueguen B., Rouxel O., Ponzevera E., Sorensen J.V., Toner B.M., Bekker A. and Fouquet Y. (2011)

$\mathrm{Ni}$ biogeochemical cycle through geological time: Insights from $\mathrm{Ni}$ isotope variations in modern and ancient marine metallifereous deposits. AGU Fall Meeting 2011, San Francisco, USA.

(C) 2013 The Authors. Geostandards and Geoanalytical Research (C) 2013 International Association of Geoanalysts 
Hofmann A., Bekker A., Dirks P., Gueguen B., Rouxel O.J. and Rumble D. (Submitted to Mineralium Deposita)

Comparing orthomagmatic and hydrothermal mineralization models of komatiite-hosted nickel deposits in Zimbabwe using multiple-sulfur, iron and nickel isotope data. Mineralium Deposita.

Horner T.J., Schönbächler M., Rehkämper M., Nielsen S.G., Williams H., Halliday A.N., Xue Z. and Hein J.R. (2010)

Ferromanganese crusts as archives of deep water Cd isotope compositions. Geochemistry Geophysics Geosystems, 11, 1525-2027.

\section{Houlé M., Lesher C.M. and Davis P. (2012)}

Thermomechanical erosion at the Alexo Mine, Abitibi greenstone belt, Ontario: Implications for the genesis of komatiite-associated $\mathrm{Ni}-\mathrm{Cu}-(\mathrm{PGE})$ mineralization. Mineralium Deposita, 47, $105-128$.

\section{Huh M.C., Lazar C., Young E.D. and Manning C.E. (2009)}

High temperature fractionation of $\mathrm{Ni}$ stable isotopes between metal and silicates: Constraints from experimental study at $800{ }^{\circ} \mathrm{C}$ and $10 \mathrm{kbar}$. EOS Transactions AGU, 90.

Kurz M.D., Jenkins W.J., Hart S.R. and Clague D. (1983)

Helium isotopic variations in volcanic rocks from Loihi seamount and the island of Hawaii. Earth and Planetary Science Letters, 66, 388-406.

\section{Marechal C.N., Télouk P. and Albarède F. (1999)}

Precise analysis of copper and zinc isotopic compositions by plasma-source mass spectrometry. Chemical Geology, 156, 251-273.

\section{Morand P. and Allegre C.J. (1983)}

Nickel isotopic studies in meteorites. Earth and Planetary Science Letters, 63, 167-176.

Moynier F., Blichert-Toft J., Télouk P., Luck J.M. and Albarède F. (2007)

(C) 2013 The Authors. Geostandards and Geoanalytical Research @ 2013 International Association of Geoanalysts 
Comparative stable isotope geochemistry of $\mathrm{Ni}, \mathrm{Cu}, \mathrm{Zn}$, and $\mathrm{Fe}$ in chondrites and iron meteorites. Geochimica et Cosmochimica Acta, 71, 4365-4379.

Muir J.E. and Comba C.D.A. (1979)

The Dundonald deposit: An example of volcanic-type nickel-sulfide mineralization. Canadian Mineralogist, 17, 351-359.

Naldrett A.J. and Mason G.D. (1968)

Contrasting Archaean ultramafic igneous bodies in Dundonald and Clergue Townships, Ontario. Canadian Journal of Earth Sciences, 5, 111-143.

\section{Nielsen S.G., Rehkämper M., Baker J. and Halliday A.N. (2004)}

The precise and accurate determination of thallium isotope compositions and concentrations for water samples by MC-ICP-MS. Chemical Geology, 204, 109-124.

Plank T., Ludden J.N. et al. (2000)

Site 1149. Proceedings of the Ocean Drilling Program, Part A: Initial Reports, 185.

Quitté G., Meier M., Latkoczy C., Halliday A.N. and Günther D. (2006)

Nickel isotopes in iron meteorites-nucleosynthetic anomalies in sulphides with no effects in metals and no trace of ${ }^{60} \mathrm{Fe}$. Earth and Planetary Science Letters, 242, 16-25.

Regelous M., Elliott T. and Coath C.D. (2008)

Nickel isotope heterogeneity in the early Solar System. Earth and Planetary Science Letters, 272, 330-338.

\section{Rehkämper M., Frank M., Hein J.R., Porcelli D., Halliday A., Ingri J. and Liebetrau V.} (2002)

Thallium isotope variations in seawater and hydrogenetic, diagenetic, and hydrothermal ferromanganese deposits. Earth and Planetary Science Letters, 197, 65-81.

(C) 2013 The Authors. Geostandards and Geoanalytical Research @ 2013 International Association of Geoanalysts 
Rosengren N., Cas R.A.F., Beresford S.W. and Palich B.M. (2008)

Reconstruction of an extensive Archaean dacitic submarine volcanic complex associated with the komatiite-hosted Mt Keith nickel deposit, Agnew-Wiluna Greenstone Belt, Yilgarn Craton, Western Australia. Precambrian Research, 161, 34-52.

Rouxel O., Dobbek N., Ludden J. and Fouquet Y. (2003)

Iron isotope fractionation during oceanic crust alteration. Chemical Geology, 202, 155-182.

Rouxel O., Fouquet Y. and Ludden J.N. (2004)

Copper isotope systematics of the Lucky Strike, Rainbow, and Logatchev sea-floor hydrothermal fields on the Mid-Atlantic Ridge. Economic Geology and the Bulletin of the Society of Economic Geologists, 99, 585-600.

Rudge J.F., Reynolds B.C. and Bourdon B. (2009)

The double spike toolbox. Chemical Geology, 265, 420-431.

Rugel G., Faestermann T., Knie K., Korschinek G., Poutivtsev M., Schumann D., Kivel N., Günther-Leopold I., Weinreich R. and Wohlmuther M. (2009)

New measurement of the ${ }^{60} \mathrm{Fe}$ half-life. Physical Review Letters, 103, 072502.

Schmitt A.D., Galer S.J.G. and Abouchami W. (2009)

Mass-dependent cadmium isotopic variations in nature with emphasis on the marine environment. Earth and Planetary Science Letters, 277, 262-272.

Scott C., Lyons T.W., Bekker A., Shen Y., Poulton S.W., Chu X. and Anbar A.D. (2008)

Tracing the stepwise oxygenation of the Proterozoic ocean. Nature, 452, 456-U5.

Scott C.T., Bekker A., Reinhard C.T., Schnetger B., Krapez B., Rumble D. and Lyons T.W. (2011)

(C) 2013 The Authors. Geostandards and Geoanalytical Research (C) 2013 International Association of Geoanalysts 
Late Archean euxinic conditions before the rise of atmospheric oxygen. Geology, 39, 119-122.

Shimamura T. and Lugmair G.W. (1983)

$\mathrm{Ni}$ isotopic compositions in Allende and other meteorites. Earth and Planetary Science

Letters, 63, 177-188.

Siebert C., Nägler T.F. and Kramers J.D. (2001)

Determination of molybdenum isotope fractionation by double-spike multicollector inductively coupled plasma-mass spectrometry. Geochemistry Geophysics Geosystems, 2, 1032.

\section{Steele R.C.J., Elliott T., Coath C.D. and Regelous M. (2011)}

Confirmation of mass-independent $\mathrm{Ni}$ isotopic variability in iron meteorites. Geochimica et Cosmochimica Acta, 75, 7906-7925.

\section{Tanimizu M. and Hirata T. (2006)}

Determination of natural isotopic variation in nickel using inductively coupled plasma-mass spectrometry. Journal of Analytical Atomic Spectrometry, 21, 1423-1426.

Teng F.Z., Dauphas N. and Helz R.T. (2008)

Iron isotope fractionation during magmatic differentiation in Kilauea Iki Lava Lake. Science, 320, $1620-1622$.

\section{Tribovillard N., Algeo T.J., Lyons T. and Riboulleau A. (2006)}

Trace metals as paleoredox and paleoproductivity proxies: An update. Chemical Geology, 232, $12-32$.

\section{Turekian K.K. and Wedepohl K.H. (1961)}

Distribution of the elements in some major units of the Earth's crust. Geological Society of America Bulletin, 72, 175-192.

(C) 2013 The Authors. Geostandards and Geoanalytical Research (c) 2013 International Association of Geoanalysts 


\section{Young E.D. and Galy A. (2004)}

The isotope geochemistry and cosmochemistry of magnesium. Reviews in Mineralogy and Geochemistry, 55, 197-230.

\section{Figure captions}

Figure 1. Plot of two standard errors (2SE) of delta values versus Ni concentration (in $\mathrm{ng} \mathrm{g}^{-1}$ ) of NIST SRM 986. These measurements were done to assess the effect of Ni concentration on the precision of the determination of $\mathrm{Ni}$ isotopes. Nickel concentration in solution above $40 \mathrm{ng} \mathrm{g}^{-1}$ during MC-ICP-MS analysis was necessary to obtain satisfactory precision, i.e., $2 \mathrm{SE}<0.06 \%$ shown on the figure by the grey band (see text for further details).

Figure 2. Isotopic composition of the mono-elemental standard solution Ni PlasmaCal@ after it was processed through chemistry. This standard solution was run along with each sample batch. This figure shows the consistency of the measured value even when different amounts of nickel were processed. The dashed lines indicate the range of $2 s(2 s=0.07 \%$ o for 24 data points) calculated for the mean of $\mathrm{Ni}$ delta values of $\mathrm{Ni}$ PlasmaCal®.

Figure 3. Plot of NIST SRM 986 delta values versus different spike/sample ratios. Under-spiked samples (ratios below 0.6) were found not to be correctly calculated by the double-spike method (wide error bars and non-zero delta values), whereas over-spiked samples up to a ratio of 7 were still correctly determined (see text for details). The black line stands for the isotopic composition of NIST SRM $986, \delta^{60 / 58} \mathrm{Ni}=0.00 \%$.

Figure 4. Comparison of values obtained with the $\mathrm{Cu}$-doping and double-spike correction methods. The 1:1 linear trend was plotted on the figure to show that data points follow this line. It indicates the consistency of the two methods, but more importantly it validates use of the double-spike method for correction of instrumental mass bias when Ni isotope ratios are measured (see text for details on each method).

Figure 5. Plot showing Ni isotope composition in \%o of terrestrial samples from this study and the literature. RMs, komatiites and associated $\mathrm{Ni}$-sulfide mineralisation, mantle-derived rocks and deep-sea clays are shown by closed symbols, and literature data for both extraterrestrial and terrestrial materials are represented by open symbols (Cook et al. 2007, Moynier et al. 2007, Cameron et al. 2009, Steele et al. 2011). The grey bar stands for the BSE $\delta^{60 / 58} \mathrm{Ni}$ value of $0.05 \pm$ $0.05 \%$, determined using various igneous and volcanic rocks and minerals such as altered and fresh basalts, dunite, peridotite, deep-sea clays and olivine crystals. See text for further details.

(C) 2013 The Authors. Geostandards and Geoanalytical Research (c) 2013 International Association of Geoanalysts 
Table 1.

Nickel isotopic composition (in \%o) of NIST SRM 986 solutions doped in Ca, S or Fe

\begin{tabular}{|c|c|c|c|}
\hline Doped element & $\begin{array}{c}\text { Element/Ni } \\
\text { ratio }\end{array}$ & ర $^{60158} \mathbf{N i}(\%)^{*}$ & $\mathbf{2 s}^{\mathbf{*}}$ \\
\hline $\mathrm{Ca}$ & 0.5 & -0.19 & 0.14 \\
$\mathrm{Ca}$ & 1 & -0.18 & 0.14 \\
$\mathrm{Ca}$ & 2 & -0.05 & 0.14 \\
$\mathrm{~S}$ & 0.5 & -0.01 & 0.14 \\
$\mathrm{~S}$ & 1 & -0.02 & 0.14 \\
$\mathrm{~S}$ & 2 & -0.06 & 0.14 \\
$\mathrm{Fe}$ & 0.001 & -0.11 & 0.09 \\
$\mathrm{Fe}$ & 0.01 & -0.06 & 0.09 \\
$\mathrm{Fe}$ & 0.001 & -0.05 & 0.09 \\
$\mathrm{Fe}$ & 0.01 & -0.09 & 0.09 \\
\hline
\end{tabular}

'The elemental ratio corresponds to a ratio of element concentrations in the solution analysed by MC-ICP-MS.

" Isotopic compositions of NIST SRM 986 Fe doped solutions calculated without application of the Fe correction.

'" $2 s$ is the two standard deviation value calculated for all pure NIST SRM 986 solutions analysed during the session in calibrator-sample bracketing mode.

Table 2.

Abundance (in \%) of $\mathrm{Ni}$ isotopes for NIST SRM 986 and double-spike

\begin{tabular}{|c|c|c|c|}
\hline Standard solution & Isotope & Abundance (\%) & $2 s^{* *}$ \\
\hline NIST SRM $986^{*}$ & ${ }^{58} \mathrm{Ni}$ & 68.07689 & 0.00592 \\
\hline NIST SRM $986^{*}$ & ${ }^{60} \mathrm{Ni}$ & 26.22315 & 0.00514 \\
\hline NIST SRM $986^{*}$ & ${ }^{61} \mathrm{Ni}$ & 1.13989 & 0.00043 \\
\hline NIST SRM $986^{*}$ & ${ }^{62} \mathrm{Ni}$ & 3.63453 & 0.00114 \\
\hline NIST SRM $986^{*}$ & ${ }^{64} \mathrm{Ni}$ & 0.92555 & 0.00060 \\
\hline Double-spike & ${ }^{58} \mathrm{Ni}$ & 1.05106 & 0.00071 \\
\hline Double-spike & ${ }^{60} \mathrm{Ni}$ & 0.76974 & 0.00071 \\
\hline Double-spike & ${ }^{61} \mathrm{Ni}$ & 51.28893 & 0.04432 \\
\hline Double-spike & ${ }^{62} \mathrm{Ni}$ & 46.61106 & 0.04753 \\
\hline Double-spike & ${ }^{64} \mathrm{Ni}$ & 0.27920 & 0.00055 \\
\hline
\end{tabular}

NIST SRM 986 values are from Gramlich et al. (1989).

" $2 s$ of double-spike isotopic composition is the two standard deviation value calculated from ratios of repeated measurements corrected for blank and Fe interference but not corrected for instrumental mass bias.

(C) 2013 The Authors. Geostandards and Geoanalytical Research (C) 2013 International Association of Geoanalysts 
Table 3.

Nickel isotope composition (in \%o) of mafic rock reference materials

\begin{tabular}{|c|c|c|c|c|c|c|}
\hline Sample name & Rock type & $\mathrm{Ni}\left(\mu \mathrm{g} \mathrm{g}^{-1}\right)^{*}$ & $\delta^{60 / 58} \mathrm{Ni}(\% \mathrm{o})$ & 2SE & $\begin{array}{l}\text { Number of } \\
\text { duplicates }\end{array}$ & $2 s^{* * *}$ \\
\hline USGS BHVO- $2^{\dagger}$ & Basalt, Hawaii & 112 & 0.014 & 0.026 & & \\
\hline USGS BHVO-2 ${ }^{t_{*}}$ & Basalt, Hawaii & 110 & 0.023 & 0.031 & & \\
\hline USGS BHVO- ${ }^{\text {H }}$ & Basalt, Hawaii & 113 & 0.049 & 0.026 & & \\
\hline USGS BHVO-2 ${ }^{\mathrm{HIt}}$ & Basalt, Hawaii & 111 & 0.020 & 0.029 & & \\
\hline USGS BHVO-2 $2^{\mathrm{Ht} \star}$ & Basalt, Hawaii & 108 & -0.011 & 0.029 & & \\
\hline USGS BHVO-2 ${ }^{\mathrm{HIt}}$ & Basalt, Hawaii & 110 & 0.003 & 0.029 & & \\
\hline usGS BHVO-2 ${ }^{1111+}$ & Basalt, Hawaii & 115 & -0.003 & 0.019 & & \\
\hline USGS BHVO- $2^{\mathrm{fll1t} *}$ & Basalt, Hawaii & 115 & 0.006 & 0.027 & & \\
\hline USGS BHVO-2 ${ }^{\mathrm{HIH}}$ & Basalt, Hawaii & 112 & -0.006 & 0.036 & & \\
\hline USGS BHVO-2 ${ }^{\mathrm{HIIt} *}$ & Basalt, Hawaii & 114 & -0.003 & 0.036 & & \\
\hline $\begin{array}{l}\text { USGS BHVO-2 }{ }^{\mathrm{HIH}{ }^{*}} \\
\text { Average BHVO-2 }\end{array}$ & Basalt, Hawaii & 112 & $\begin{array}{l}-0.030 \\
0.006\end{array}$ & $\begin{array}{c}0.032 \\
-\end{array}$ & $n=11$ & 0.041 \\
\hline USGS BHVO-2 $2^{\text {IIIS }}$ & Basalt, Hawaii & 105 & -0.067 & 0.017 & & \\
\hline USGS BIR-1 ${ }^{\dagger}$ & Basalt, lceland & 159 & 0.105 & 0.020 & & \\
\hline USGS BIR-1 $1^{t_{*}}$ & Basalt, Iceland & 159 & 0.115 & 0.026 & & \\
\hline USGS BIR-1 ${ }^{H I}$ & Basalt, lceland & 165 & 0.140 & 0.020 & & \\
\hline Average BIR-1 & & & 0.120 & - & $\mathrm{n}=3$ & 0.035 \\
\hline USGS DNC-1 ${ }^{\dagger}$ & Dolerite & 242 & 0.165 & 0.027 & & \\
\hline USGS DNC- $1^{\dagger *}$ & Dolerite & 244 & 0.115 & 0.023 & & \\
\hline USGS DNC-1 ${ }^{\text {Ht }}$ & Dolerite & 239 & 0.118 & 0.021 & & \\
\hline Average DNC-1 & & & 0.132 & - & $n=3$ & 0.056 \\
\hline USGS DTS-1 ${ }^{\dagger}$ & Dunite & 2327 & -0.061 & 0.028 & & \\
\hline USGS DTS- $1^{t_{\star}}$ & Dunite & 2451 & -0.100 & 0.026 & & \\
\hline USGS DTS- $1^{\text {Ht }}$ & Dunite & 2171 & -0.083 & 0.022 & & \\
\hline USGS DTS- 1 tIt & Dunite & 2199 & -0.039 & 0.034 & & \\
\hline Average DTS-1 & & & -0.071 & - & $n=4$ & 0.053 \\
\hline USGS PCC-1 ${ }^{\dagger}$ & Peridotite & 2245 & 0.111 & 0.035 & & \\
\hline USGS PCC- $1^{t_{\star}}$ & Peridotite & 2369 & 0.100 & 0.026 & & \\
\hline USGS PCC- $1^{t_{*}}$ & Peridotite & 2188 & 0.149 & 0.022 & & \\
\hline USGS PCC-1 & Peridotite & 2204 & 0.097 & 0.023 & & \\
\hline USGS PCC-1 ${ }^{\dagger}$ & Peridotite & 2241 & 0.136 & 0.043 & & \\
\hline Average PCC-1 & & & 0.119 & - & $n=5$ & 0.045 \\
\hline
\end{tabular}

This symbol denotes the archive solution of a digested sample that was processed several times through the identical procedure of chemical purification in order to obtain duplicates of the same sample that were processed through the same chemistry. ${ }^{\dagger}$ This symbol stands for different powder digestions, e.g., five digestions were made for BHVO-2 and two digestions for PCC-1.

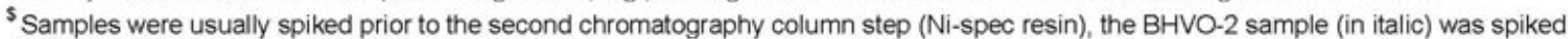
only after the entire procedure of purification.

"Ni concentration (in $\mu \mathrm{g} \mathrm{g}^{-1}$ ) were determined by isotope dilution after measurement on MC-ICP-MS. Amount of Ni processed through chemistry was between 0.5 and $25 \mu \mathrm{g}$.

"' Two standard deviation ( $2 s$ ) calculated on values of the whole batch of identical samples (see text); number of samples ( $n$ ) is specified.

(C) 2013 The Authors. Geostandards and Geoanalytical Research (C) 2013 International Association of Geoanalysts 
Table 4.

Concentration of some major elements (in $\mu g g^{-4}$ ) and Ni isotope composition (in \%os) of basaltic glass and olvine from Loihi and serpentinite from the Logatcher hydrothermal field

\begin{tabular}{|c|c|c|c|c|c|c|c|c|c|c|c|c|}
\hline Sample name & Rocktype & Al $\left(\log g^{*}\right)^{*}$ & $\mathrm{Ca}\left(\log g^{-1}\right)^{\circ}$ & $\mathrm{Mg}\left(\log g^{-4}\right)^{*}$ & $\mathrm{Na}\left(\text { (ug } g^{\circ}\right)^{*}$ & $\operatorname{Mn}\left(\mu g^{\circ}\right)^{\circ}$ & $\mathrm{Fe}\left(\log g^{4}\right)^{*}$ & Co(pgg $)^{\circ}$ & $\ln \left(\operatorname{\mu g} g^{4}\right)^{*}$ & Ni $\left(\lg g^{4}\right)^{\prime \prime}$ & $8^{6079} \mathrm{Ni}\left(\mathrm{H}_{0}\right)$ & 2SE \\
\hline Basatic glass (Loh) & Basalt, Hawai & 51291 & 70609 & 98084 & 15661 & 1329 & 91013 & 80 & 110 & 603 & 0.074 & 0002 \\
\hline Olwne minerals fractions (Lahi) & Oline minerals & 322 & 2348 & 280653 & 51 & 1500 & 104045 & 163 & 88 & 2250 & 0.104 & 00030 \\
\hline Serpertinte (Logatchev hydrothermal fielo) & Serpertinte, Allarto & 2520 & 622 & 159862 & 2001 & 399 & 151144 & 473 & 1378 & 1505 & -0126 & 0006 \\
\hline
\end{tabular}

Eemental concertrations (in pg g.") were determined by ICP.AES at PSO, Brest, France Precision expressed as RSO was between $0.5 \%$ and $3 \%$

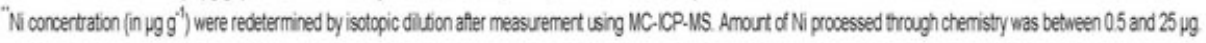

Table 5.

Nickel isotope compostion (in \%o) and major element concentrations (in \% m/m) of deep-sea clays and atered and fresh basalts from 100P site 1149, hole C

\begin{tabular}{|c|c|c|c|c|c|c|c|c|c|c|c|c|c|c|c|c|}
\hline Sample name & $\begin{array}{c}\text { Depth }(m) \text { in } \\
\text { the cose }\end{array}$ & Sample tipe & เo| & $K \neq 0$ & $\mathrm{Fe} \mathrm{O}_{3}$ & $\mathrm{SO}_{2}$ & $\mathrm{C} 30$ & Ibo & Ino & $\mathrm{Na}_{2} \mathrm{O}$ & $P_{2} \mathrm{P}_{3}$ & $\mathrm{AL}_{2} \mathrm{O}_{3}$ & $\mathrm{TO}_{2}$ & 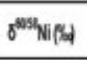 & $2 S E$ & Ni (jgg')" \\
\hline $1148 \mathrm{~A}-01 \mathrm{H} 1,140$ & 14 & Ash ard sica bearing dey & 912 & 1.88 & 548 & 5850 & 301 & 236 & 012 & 3,14 & 007 & 1488 & 0.57 & 0044 & 00037 & 33 \\
\hline $1149,-042,140$ & 28.1 & $\mathrm{Cay}$ & 11.06 & 253 & 7.08 & $57 \pi$ & 1.45 & $2 \pi$ & 012 & 274 & 0.10 & 1428 & 064 & 0000 & 00034 & 55 \\
\hline $1148-32 R 1,138$ & 48856 & Atered besat & 500 & 0.57 & 1027 & 4750 & 8.41 & 6.68 & 011 & 284 & 0.20 & 16.16 & 1.79 & 0018 & 0002 & 73 \\
\hline $11.98 .2993,600$ & 4031 & Basat sightly atered & 213 & 0.18 & 7.90 & 5034 & 11.12 & 790 & 0.14 & 270 & 022 & 15.4 & 177 & 0004 & 0.041 & 71 \\
\hline $1180,19 R 1,85$ & 45557 & Deepest fiesh basat & 122 & 044 & 1317 & 4856 & 989 & 612 & 022 & 300 & 0.24 & 1496 & 231 & 0062 & 0002 & 43 \\
\hline $1140-058202$ & 31217 & Atererd basat & 200 & 0.52 & 972 & 4977 & 1000 & 700 & 014 & 264 & 0.19 & 15.16 & 174 & 0006 & 0003 & 61 \\
\hline $11480-10 \% 30$ & 48886 & Atered basat & 252 & 0.59 & 971 & 4821 & 1215 & 628 & 0.23 & 267 & 022 & 1502 & 171 & 0.102 & 0.003 & 111 \\
\hline
\end{tabular}

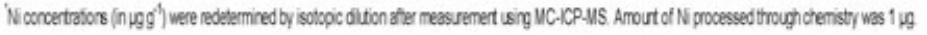


Table 6.

Nickel isotope composition (in \%o) of selected komatiites and associated Ni-sulfide mineralisation from Canada and Western Australia

\begin{tabular}{|c|c|c|c|c|c|c|c|c|c|c|c|c|}
\hline Sample name & ample locatio & Drill core \# & \begin{tabular}{|c|}
$\begin{array}{c}\text { Type of } \\
\text { mineralizatio } \\
\text { n }\end{array}$ \\
\end{tabular} & $\begin{array}{c}\text { Type of } \\
\text { komatites }\end{array}$ & $s(\% \mathrm{~m} / \mathrm{m})^{\prime \prime}$ & $\left.F_{e}(\% \mathrm{~m} / \mathrm{m})\right)^{\prime \prime}$ & $\mathrm{Cu}(\% \mathrm{~m} / \mathrm{m})^{-1}$ & Ni $\left(\mu g^{-4}\right)^{-1 *}$ & $\delta^{\operatorname{con} 14} \mathrm{Ni}\left(\mathrm{\gamma}_{\mathrm{m}}\right)$ & 2SE & $\sigma^{50 / 3} \mathrm{Fe}\left(X_{0}\right)$ & $\Delta^{32 n} S\left(\psi_{\infty}\right)^{-}$ \\
\hline BE-1 & $\begin{array}{l}\text { Bettheno, } \\
\text { Yakabindie, } \\
\text { Agnew-Wiluna } \\
\text { Belt, Yilgarn } \\
\text { Craton, } \\
\text { Western } \\
\text { Australia }\end{array}$ & MKTD 528 & Olivine & $\begin{array}{c}\text { Barren } \\
\text { komatites }\end{array}$ & 0.36 & 50 & $<D L$ & 7253 & -0.256 & 0.024 & -0.05 & - \\
\hline$B E-2$ & \begin{tabular}{|l|} 
Betheno, \\
Yakabindie, \\
Agnew-Wiluna \\
Belt, Yilgarn \\
Craton, \\
Western \\
Australia
\end{tabular} & MKTD 528 & Oivine & $\begin{array}{c}\text { Barren } \\
\text { komatites }\end{array}$ & 0.36 & 50 & $<\mathrm{DL}$ & 8692 & -0.243 & 0.028 & -0.02 & - \\
\hline A & $\begin{array}{l}\text { Jordan, Albion } \\
\text { Downs, Agnew } \\
\text { Wiluna Bet, } \\
\text { Yilgarn } \\
\text { Craton, } \\
\text { Western } \\
\text { Australia }\end{array}$ & ADNO 348 & $\begin{array}{c}\text { Disseminated } \\
\text { sulfides }\end{array}$ & $\begin{array}{c}\text { Barren } \\
\text { komatites }\end{array}$ & 0.87 & - & 0.62 & 3893 & -0.103 & 0.024 & - & -0.1 \\
\hline$A X-1$ & \begin{tabular}{|l|} 
Alexo Mine, \\
Abitibi \\
Greenstone \\
Belt, Canada \\
Alexo Mine,
\end{tabular} & - & $\begin{array}{c}\text { Massive } \\
\text { sulfide ores }\end{array}$ & des bearing kor & - & 53,15 & 1.04 & 58693 & -1.003 & 0.029 & -0.29 & -0.9 \\
\hline$A X-2$ & \begin{tabular}{|l|} 
Abitibi \\
Greenstone \\
Belt, Canada
\end{tabular} & - & $\begin{array}{c}\text { Massive } \\
\text { sulfide cres }\end{array}$ & des bearing kor & - & 52.4 & 1.61 & 71462 & -1.035 & 0.034 & -0.30 & -0.8 \\
\hline MC-1 & $\begin{array}{l}\text { Mount } \\
\text { Newman, } \\
\text { Mount Cilford, } \\
\text { Agnew-Wiluna } \\
\text { Beit, Yilgarn } \\
\text { Craton, } \\
\text { Western } \\
\text { Australia }\end{array}$ & LMCD005 & Blebby sulides & des bearing kor & 1.07 & 21.7 & 1.70 & 82159 & -0.621 & 0.029 & 0.03 & -0.5 \\
\hline
\end{tabular}

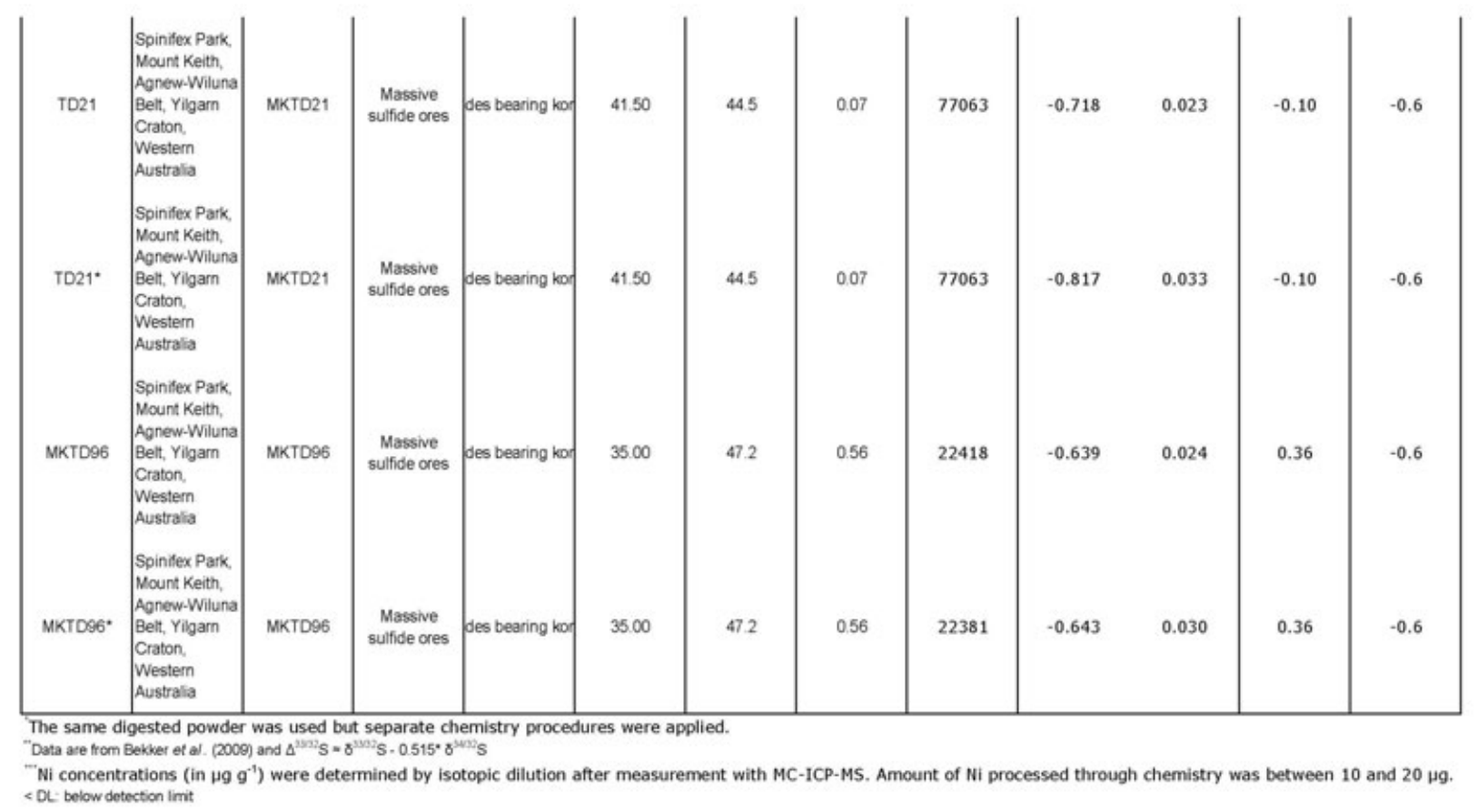

(C) 2013 The Authors. Geostandards and Geoanalytical Research (C) 2013 International Association of Geoanalysts 
Table 7.

Nickel isotope composition (in \%o) of iron meteorites, granite G-2 and selected geological reference materials of sedimentary origin

\begin{tabular}{|c|c|c|c|c|c|c|}
\hline Sample name & Rock type & $\mathrm{Ni}\left(\mu \mathrm{g} \mathrm{g}^{-1}\right){ }^{*}$ & $\delta^{60 / 58} \mathrm{Ni}(\%)$ & 2SE & $\begin{array}{l}\text { Number of } \\
\text { duplicates }\end{array}$ & $2 s^{m}$ \\
\hline USGS G-2 & Granite & 2 & 0.431 & 0.034 & & \\
\hline Nantan Iron & iron meteorite (IICD) & 58328 & 0.331 & 0.022 & & \\
\hline Nantan Iron & iron meteorite (IICD) & 59370 & 0.301 & 0.029 & & \\
\hline Nantan Iron & iron meteorite (IICD) & 61239 & 0.313 & 0.030 & & \\
\hline Average Nantan Iron & & 59645 & 0.315 & - & $\mathrm{n}=\mathbf{3}$ & 0.030 \\
\hline Gibeon Iron & iron meteorite (IVA) & 69314 & 0.284 & 0.026 & & \\
\hline Gibeon Iron' & iron meteorite (IVA) & 82959 & 0.239 & 0.026 & & \\
\hline Gibeon Iron & iron meteorite (IVA) & 74133 & 0.255 & 0.032 & & \\
\hline Average Gibeon Iron & & 75469 & 0.260 & - & $\mathrm{n}=\mathbf{3}$ & 0.045 \\
\hline USGS Nod-A-1 ${ }^{\dagger}$ & Mn-nodule Atlantic & 5616 & 1.034 & 0.028 & & \\
\hline USGS Nod-A-1 ${ }^{+}$ & Mn-nodule Atlantic & 5413 & 1.062 & 0.031 & & \\
\hline USGS Nod-A-1 ${ }^{\mathrm{Ht}}$ & Mn-nodule Atlantic & 5633 & 1.043 & 0.026 & & \\
\hline USGS Nod-A-1 ${ }^{t+}$ & Mn-nodule Atlantic & 5778 & 1.043 & 0.028 & & \\
\hline USGS Nod-A-1 ${ }^{+}$ & Mn-nodule Atlantic & 5513 & 1.043 & 0.031 & & \\
\hline USGS Nod-A-1 ${ }^{t+}$ & Mn-nodule Atlantic & 5334 & 0.976 & 0.031 & & \\
\hline $\begin{array}{c}\text { Average Mn-nodule } \\
\text { Atlantic }\end{array}$ & & 5548 & 1.034 & - & $n=6$ & 0.059 \\
\hline USGS Nod-P-1 ${ }^{\dagger}$ & Mn-nodule Pacific & 12330 & 0.347 & 0.028 & & \\
\hline USGS Nod-P-1 ${ }^{+*}$ & Mn-nodule Pacific & 11961 & 0.412 & 0.028 & & \\
\hline USGS Nod-P-1 ${ }^{t+}$ & Mn-nodule Pacific & 12208 & 0.401 & 0.034 & & \\
\hline USGS Nod-P-1 ${ }^{H+}$ & Mn-nodule Pacific & 12454 & 0.345 & 0.029 & & \\
\hline USGS Nod-P-1 ${ }^{\dagger}$ & Mn-nodule Pacific & 12165 & 0.363 & 0.025 & & \\
\hline USGS Nod-P-1 ${ }^{t+}$ & Mn-nodule Pacific & 12482 & 0.343 & 0.039 & & \\
\hline USGS Nod-P-1†* & Mn-nodule Pacific & 12605 & 0.304 & 0.032 & & \\
\hline USGS Nod-P-1 $1 \dagger^{\star}$ & Mn-nodule Pacific & 11553 & 0.349 & 0.038 & & \\
\hline $\begin{array}{l}\text { Average Mn-nodule } \\
\text { Pacific }\end{array}$ & & 12220 & 0.358 & - & $\mathrm{n}=\mathbf{8}$ & 0.069 \\
\hline USGS SDO-1 & Devonian shale & 92 & 0.600 & 0.021 & & \\
\hline USGS SDO-1' & Devonian shale & 95 & 0.593 & 0.040 & & \\
\hline USGS SDO- $1^{\circ}$ & Devonian shale & 85 & 0.576 & 0.030 & & \\
\hline USGS SDO-1 & Devonian shale & 91 & 0.583 & 0.036 & & \\
\hline USGS SDO- $1^{\circ}$ & Devonian shale & 91 & 0.571 & 0.031 & & \\
\hline Average SDO-1 & & 91 & 0.585 & - & $\mathbf{n}=\mathbf{5}$ & 0.025 \\
\hline USGS CLB-1 & Coal & 20 & 0.475 & 0.018 & & \\
\hline USGS CLB-1" & Coal & 21 & 0.502 & 0.046 & & \\
\hline USGS CLB-1 & Coal & 21 & 0.470 & 0.027 & & \\
\hline USGS CLB-1" & Coal & 21 & 0.443 & 0.042 & & \\
\hline Average CLB-1 & & 21 & 0.473 & - & $n=4$ & 0.048 \\
\hline IF-G & Banded Iron Formations & 20 & 0.455 & 0.032 & & \\
\hline NIST SRM 2711 & $\begin{array}{l}\text { Contaminated } \\
\text { Montana soil }\end{array}$ & 18 & 0.140 & 0.019 & & \\
\hline
\end{tabular}

Same as in Table 3.

"Same as in Table 3.

†Same as in Table 3.

"'same as in Table 3

(C) 2013 The Authors. Geostandards and Geoanalytical Research (C) 2013 International Association of Geoanalysts 
Table 8.

Compilation of published isotope composition of $\mathrm{Tl}, \mathrm{Mo}, \mathrm{Cd}, \mathrm{Fe}, \mathrm{Cu}$ and $\mathrm{Zn}$ in two $\mathrm{Mn}$-nodule $\mathrm{RMs}$ and $\mathrm{Ni}$ isotope data (this study)

\begin{tabular}{|c|c|c|c|c|c|}
\hline & Nod-P-1 & $2 s$ & Nod-A-1 & $2 s$ & Reference \\
\hline$\delta^{60 / 58} \mathrm{Ni}_{\text {NIST986 }}(\%)$ & 0.36 & 0.07 & 1.03 & 0.06 & This study \\
\hline$\delta^{205} \mathrm{TI}_{\mathrm{NIST} 997}(\% \circ)^{*}$ & nd & - & 1.07 & 0.05 & Nielsen et al. (2004) \\
\hline$\delta^{205} \mathrm{TI}_{\text {NIST997 }}(\% \circ)^{*}$ & 0.05 & 0.045 & 0.89 & 0.045 & Rehkämper et al. (2002 \\
\hline$\delta^{97 / 95} \mathrm{Mo}_{\text {JMC-spec }}(\% \mathrm{O})$ & -0.42 & 0.1 & -0.63 & 0.1 & Barling et al. (2001) \\
\hline${ }^{14 / 110} \mathrm{Cd}_{\text {JMC-Cd-Mainz }}(\%)$ & 0.020 & $0.016^{\prime \prime}$ & -0.018 & $0.016^{*}$ & Schmitt et al. (2009) \\
\hline $5^{114 / 110} \mathrm{Cd}_{\text {JMC-Cd-affa }}(\% \mathrm{O})$ & 0.22 & $0.06^{* *}$ & 0.25 & $0.06^{*}$ & Horner et al. (2010) \\
\hline$\delta^{114 / 110} \mathrm{Cd}_{\mathrm{Cd}-\mathrm{SPEX}}(\% \propto)^{\mathrm{s}}$ & 0.13 & $0.12^{\prime \prime}$ & -0.07 & $0.12^{\prime \prime}$ & Cloquet et al. (2005) \\
\hline$\delta^{56 / 54} \mathrm{Fe}_{\text {IRMM-14 }}(\%)$ & -0.50 & 0.10 & -0.35 & 0.09 & Rouxel, unpubl. \\
\hline$\delta^{56 / 54} \mathrm{Fe}_{\text {IRMM-14 }}(\%)$ & nd & - & -0.42 & 0.07 & Dideriksen et al. (2006) \\
\hline$\delta^{65 / 63} \mathrm{Cu}_{\text {NIST976 }}(\%)$ & 0.46 & 0.08 & nd & - & Chapman et al. (2006) \\
\hline$\delta^{65 / 63} \mathrm{Cu}_{\text {NIST976 }}(\%)$ & 0.35 & 0.08 & nd & - & Bigalke et al. (2010) \\
\hline$\delta^{66 / 64} \mathrm{Zn}_{\mathrm{JMC}-\mathrm{Zn}}(\%)$ & 0.78 & 0.09 & nd & - & Chapman et al. (2006) \\
\hline$\delta^{66 / 64} \mathrm{Zn}_{\operatorname{MMC}-\mathrm{Zn}}(\% \mathrm{O})$ & 0.87 & 0.08 & nd & - & Bigalke et al. (2010) \\
\hline
\end{tabular}

nd: not-determined

'Isotope ratios were initially reported in per thousand in epsilon notation. For clarity, values are given here in per mil to express values in delta notation.

"Measurement precision is expressed as two standard error of the mean.

${ }^{\dagger}$ Data from Schmitt et al. (2009) were originally reported as ${ }^{112 / 110} \mathrm{Cd}$ ratio. For more comparison with other Cd data, the data were converted to delta values expressing them as the $114 / 110 \mathrm{Cd}$ ratio.

${ }^{5}$ Note that $\mathrm{Cd}$ isotope compositions for the three references are reported relative to different reference materials (JMC-Mainz, JMC Alfa Zürich, Spex).

(C) 2013 The Authors. Geostandards and Geoanalytical Research (C) 2013 International Association of Geoanalysts 

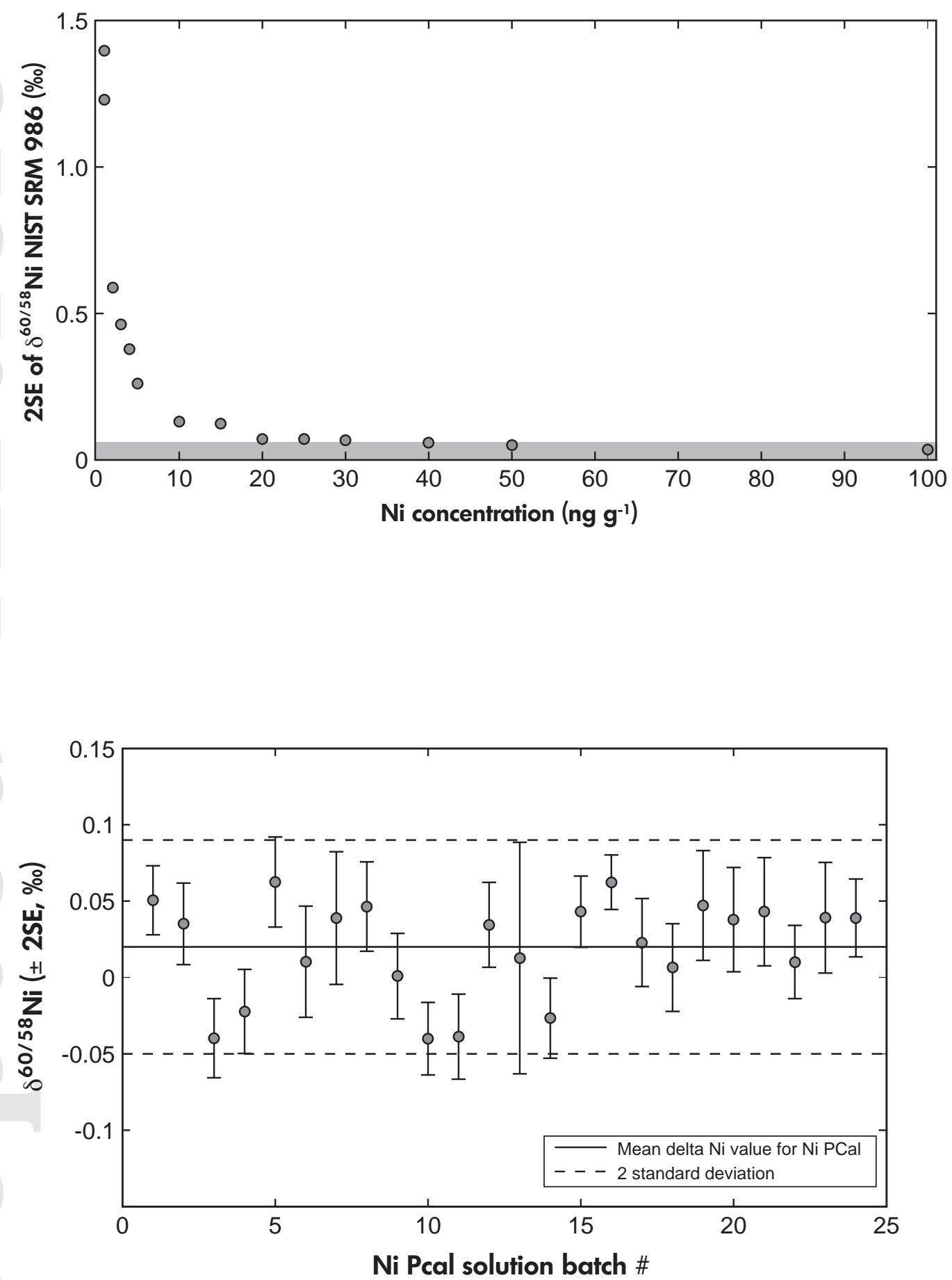

(C) 2013 The Authors. Geostandards and Geoanalytical Research () 2013 International Association of Geoanalysts 

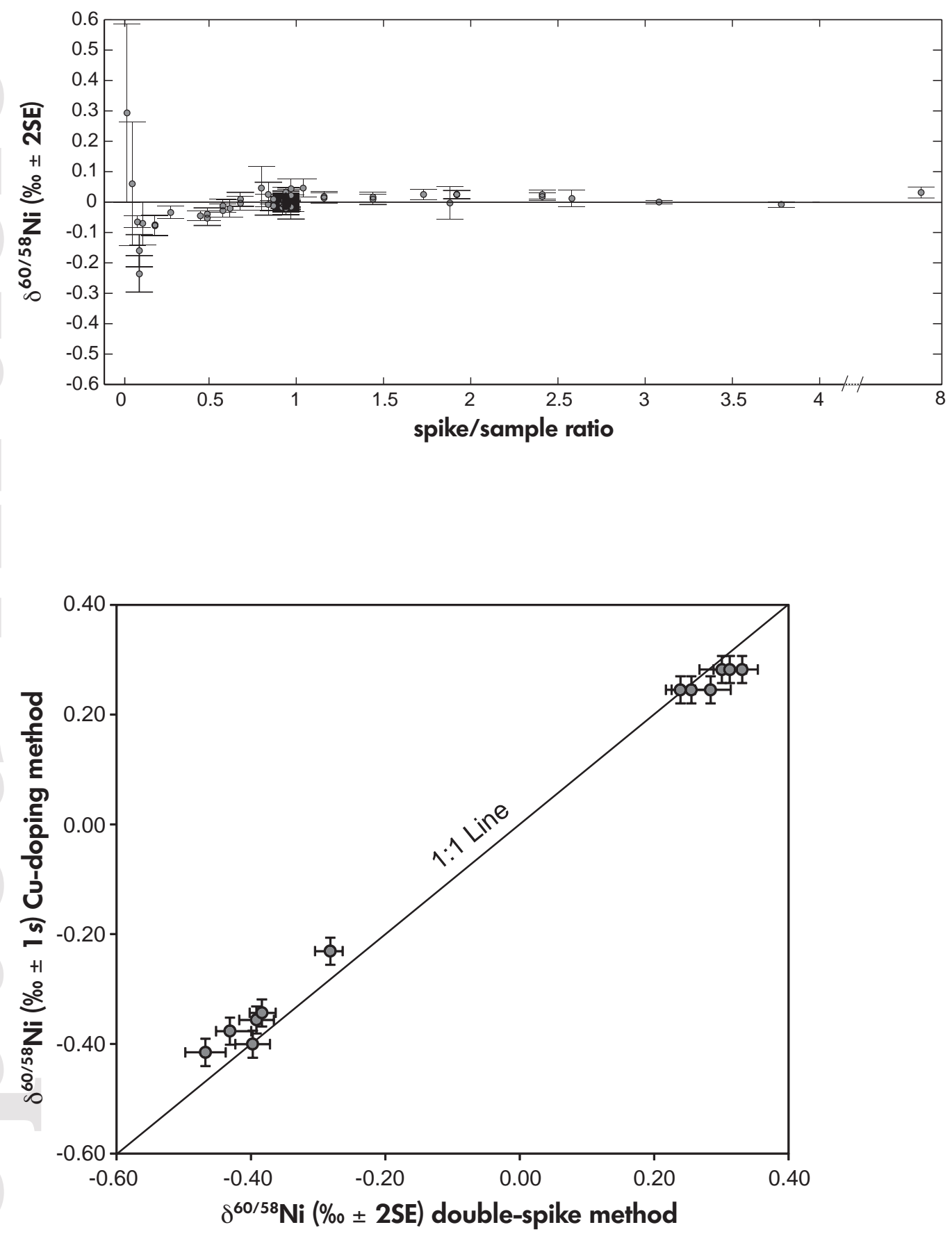

(C) 2013 The Authors. Geostandards and Geoanalytical Research () 2013 International Association of Geoanalysts 
$\delta^{60 / 58} \mathrm{Ni}(\%)$

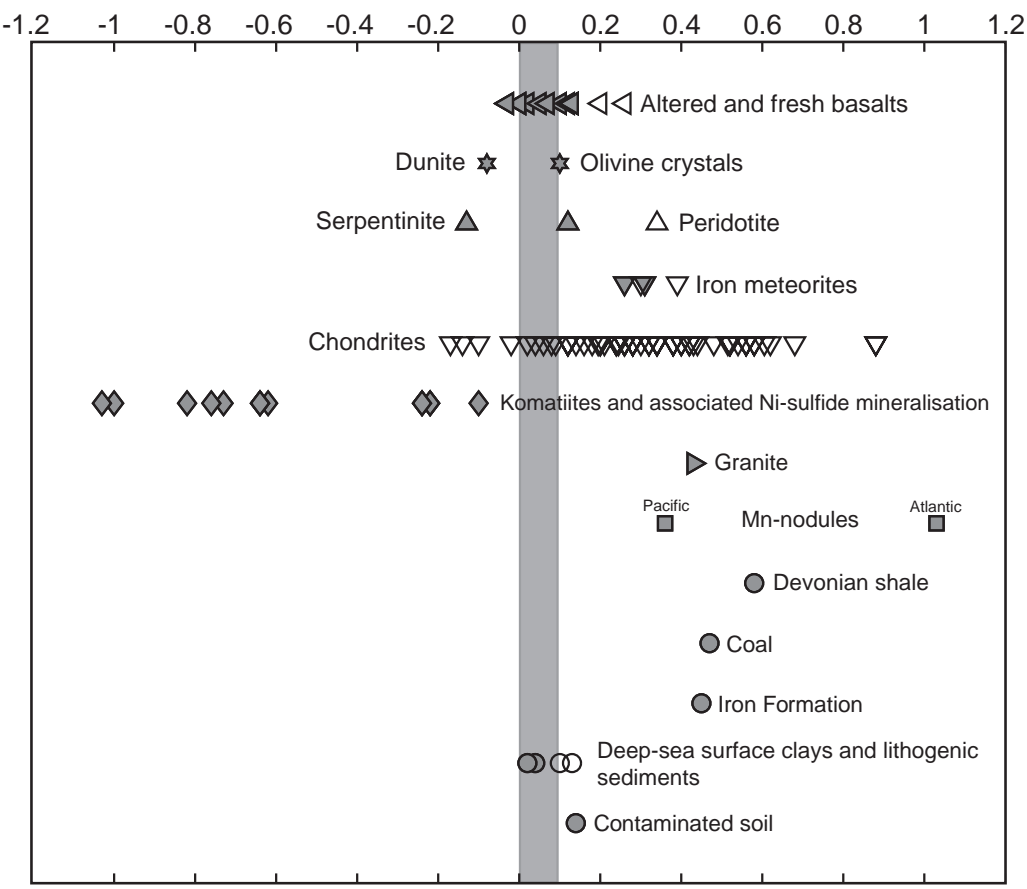

(C) 2013 The Authors. Geostandards and Geoanalytical Research (C) 2013 International Association of Geoanalysts 